\title{
Theoretical investigation of the complexation, structural, and electronic properties of complexes between oseltamivir drug and cucurbit[n = 6-9]urils
}

\section{Wandee Rakrai}

Rajabhat Maha Sarakham University: Rajabhat Mahasarakham University

Chanukorn Tabtimsai

Rajabhat Maha Sarakham University: Rajabhat Mahasarakham University

Chatthai Kaewtong

Mahasarakham University

Banchob Wanno ( $\nabla$ banchobw@gmail.com )

Mahasarakham University https://orcid.org/0000-0001-7908-7652

\section{Research Article}

Keywords: Cucurbit[n]uril, Density functional theory, Influenza virus, Host-guest complex, Oseltamivir

Posted Date: January 27th, 2022

DOI: https://doi.org/10.21203/rs.3.rs-1025546/v1

License: (c) (i) This work is licensed under a Creative Commons Attribution 4.0 International License. Read Full License

Version of Record: A version of this preprint was published at Structural Chemistry on February 10th, 2022. See the published version at https://doi.org/10.1007/s11224-022-01888-1. 


\section{Abstract}

The structural geometries of cucurbit[n]uril with $n=6-9$ and their complexes with oseltamivir (OST) drug were obtained using the density functional theory computations. The stationary points of the most stable complexes were confirmed using vibrational frequency calculation. The complexation energies and electronic properties of $\mathrm{CB}[n] / \mathrm{OST}$ complexes were investigated. The calculated results indicate that the intermolecular interactions in all the studied complexes occurring via a large number of dipole-dipole interactions, especially hydrogen bonds between oxygen atoms of $\mathrm{CB}[n]$ and hydrogen atoms of amine of oseltamivir drug. The negative complexation energies of $\mathrm{CB}[n] / \mathrm{OST}$ complexes in both gas and water phases indicate that the host-guest complexes are exothermic process and the complexes are more stable than its bare $\mathrm{CB}[n]$. In addition, the $\mathrm{CB}[7] /$ OST complex is more stable than that of all studied $\mathrm{CB}[n] / O S T$ complexes. The frequency calculation results of the most stable complexes for each of $\mathrm{CBs}$ indicate that complexations are occurred via a spontaneous process. The NBO analysis of complexes shows the transferring of partial charge from $\mathrm{CB}[n]$ s to oseltamivir which correspond to their MEP contours. The HOMO and the LUMO orbitals are localized on the oseltamivir in $\mathrm{CB}[n] / \mathrm{OST}$ complexes. After drug complexation, the electronic properties also display that, the energy gaps of $\mathrm{CB}[n]$ are significantly changed. All of the complexation properties point out here that $\mathrm{CB}[n] \mathrm{s}$ can act as a host for appropriately oseltamivir guest, even in aqueous solution.

\section{Introduction}

In the field of supramolecular chemistry, the design of drug delivery system through the host-guest formation is interested [1]. One efficiency method is the drug encapsulation with macrocyclic host. Encapsulation method can be utilized in the delivery, solubilization, and stabilization of drug [2-3]. Moreover, encapsulation can protect the drug from degradation and increases the specific of the drug [45]. Macrocyclic host for drug encapsulation has been widely interested such as cyclodextrins [6-8] calixarenes [9-10], crown ethers [11] and cucurbit[n] urils [12-15].

Cucurbit $[n]$ uril (CB[n]) compounds with the molecular formula of $\mathrm{C}_{6 \mathrm{n}} \mathrm{H}_{6 \mathrm{n}} \mathrm{N}_{4 \mathrm{n}} \mathrm{O}_{2 \mathrm{n}}$ have features of cavitands that are suitable for host-guest complex [16]. The cucurbit[ $n]$ uril hosts have been synthesized via the condensation between glycoluril and formaldehyde in strongly acidic solution [17], the homologues of cucurbit[n]urils ( $\mathrm{CB}[n], \mathrm{n}=5-10)$ included five to ten glycoluril units acting as hydrophobic cavity are favorable for holding hydrophobic groups/neutral molecules. Thus the hostguest complexes of $\mathrm{CB}[n] \mathrm{s}$ are produced via noncovalent interactions including ion-dipole interactions and hydrogen bonding interaction [18-19]. Recently, $\mathrm{CB}[n]$ compounds are widely interest for drug delivery applications through host-guest formation because the $\mathrm{CB}[n]$ and their derivatives are non-toxic [20]. There are numerous reports focusing on drug delivery of the $\mathrm{CB}[n][21-26]$. Moreover, the different aspects of the $\mathrm{CB}[n]$ chemistry, such as catalysis [27], materials [28] and other potential application in supramolecular [29] have been also reported. 
Oseltamivir (OST) has been approved by the Food and Drug Admission (FDA) in 1999 [30]. Oseltamivir is used as an antiviral drug for the treatment of influenza virus. Its action mechanism is correlated to the neuraminidase inhibition of the influenza virus [31]. In the human body, oseltamivir is transformed to oseltamivir acid which is the pharmacologically active metabolite. Oseltamivir acid is also showing indirectly photodegradable [32] and slow degradation in surface waters, but increased degradation in sediment/water systems [33-34]. Basically, when the hosts transform in the bioenvironment system their properties could be modified via oxidation, hydrolysis, or reduction phenomena, therefore it is necessary to control the releasing ability, improve bioavailability, and reduce toxic effects [35].

In the present research, we present a theoretical study on the possibility of the complexations between oseltamivir and cucurbit $[n]$ uril ( $\mathrm{CB}[n], n=6,7,8$ and 9$)$ and investigate their energetical and geometrical properties using the density functional theory (DFT) calculations. The charge transfer, energies of the highest occupied molecular orbital (HOMO), the lowest unoccupied molecular orbital (LUMO), and molecular electrostatic potential (MEP) for the species and complexes have been computed.

\section{Computational Details}

The DFT computations were employed to optimize the structures of $\mathrm{CB}[n](n=6,7,8$ and 9$)$ and their complexes with oseltamivir. All calculations were carried out with the Becke 3-parameters exchange functionals and LYP correlation functional (B3LYP) theory with the $6-31 \mathrm{G}(\mathrm{d}, \mathrm{p})$ basis set [36-38]. The complexation has been processed by putting the guest into the cavity of $\mathrm{CB}[n]$ hosts. Full geometrical optimization of the $\mathrm{CB}[n]$ and their complexation structures were performed without any geometrical or symmetry constrains in which none of the atoms were fixed. The highest occupied molecular orbital $\left(E_{\text {HOMO }}\right)$ and the lowest unoccupied molecular orbital $\left(E_{\mathrm{LUMO}}\right)$ energies were computed from the same theoretical level.

All computations were performed with the GAUSSIAN 09 program [39]. Electronic properties of all studied compounds have been computed in the gas phase unless otherwise specified. The computations of studied compounds in water, the solvent effect under the conductor-like polarizable continuum model (CPCM) [40-41] was carried out. To understand the stability of the complexes, the complexation energies $\left(E_{\mathrm{cpx}}\right)$ were obtained from the energy difference between the energy of host-guest complexes $\left(E_{\mathrm{H}-\mathrm{G}}\right)$ and energy of the bare $\mathrm{CB}[n]\left(E_{\mathrm{H}}\right)$ and free oseltamivir guest $\left(E_{\mathrm{G}}\right)$ as below:

$E_{\mathrm{cpx}}=E_{\mathrm{H}-\mathrm{G}}-\left(E_{\mathrm{H}}+E_{\mathrm{G}}\right)(1)$

The natural bond orbital (NBO) analysis implemented in GAUSSIAN 09 program has been used. The partial charge transfers (PCTs) during complexation have been defined as a change in oseltamivir charges during the complexation process using the computed natural bond orbital charges. Finally, the graphics and electrostatic potential (MEP) of studied complexes were generated using the MOLEKEL 4.3 program [42].

\section{Results And Discussion}


The geometrical structures of cucurbit $[n]$ uril $(\mathrm{CB}[n], \mathrm{n}=6,7,8$, and 9$)$ and their complexes with oseltamivir have been computed by full optimization without any constrains using the DFT method. The optimized structures of oseltamivir and bare cucurbit[n]urils are displayed in Figs. 1 and 2, respectively. The optimized structures of the $\mathrm{CB}[n] \mathrm{s}$ are found to posses as a $\mathrm{D}_{n h}$ symmetrical structure, which is in agreement with the earlier report [43]. The intramolecular depths of the cavity of $\mathrm{CB}[6], \mathrm{CB}[7], \mathrm{CB}[8]$, and $\mathrm{CB}[9]$ are $6.23,6.24,6.25$ and $6.26 \AA$, respectively. The equatorial widths are extreme and systematical increasing from 7.20 to $11.76 \AA$ with ring size. The computed intermolecular distances between the oxygen portals for $\mathrm{CB}[6], \mathrm{CB}[7], \mathrm{CB}[8]$, and $\mathrm{CB}[9]$ are $7.20,8.77,10.31$ and $11.76 \AA$, respectively which are according to the previous calculated values [16].

To investigate the possible geometries of the $\mathrm{CB}[n] / \mathrm{OST}$ complexes, an oseltamivir was placed inside the cavity of $\mathrm{CB}[n]$ with different orientations and allowed to relax. To obtain complete molecular structures of the oseltamivir orientation in the host-guest complexes, we combined the oseltamivir with $\mathrm{CB}[n]$ in different orientations before computations. Subsequently full geometry optimization was carried out. Three types of the possible host-guest inclusion modes of binding motive through ethyl formate (CB $[n] / O S T-e)$, acetamide (CB $[n] / O S T-a)$, and pentan-3-ol (CB $[n] / O S T-p)$ side chains pointing to $\mathrm{CB}[n]$ cavities are obtained. The DFT optimized structures of oseltamivir complexes with the $\mathrm{CB}[6], \mathrm{CB}[7], \mathrm{CB}[8]$, and $\mathrm{CB}[9]$ are displayed in Figs. 3, 4, 5, and 6, respectively. The optimized geometrical structures for all $\mathrm{CB}[n] / O S T$ complexes reveal that most of oseltamivir is still positioned inside the cavity of $\mathrm{CB}[6], \mathrm{CB}[7]$, and $\mathrm{CB}[8]$, except for $\mathrm{CB}[6] / O S T-a, \mathrm{CB}[6] / O S T-p$ and $\mathrm{CB}[8] / O S T-p$ complexes, oseltamivir is expelled out of $\mathrm{CB}[n]$ s. For the largest cavity host $\mathrm{CB}[9]$, only one type of optimized geometries in which OST drug placed at the cavity center of $\mathrm{CB}[9]$ is converged and obtained. The computed results also display that the $\mathrm{CB}[n]$ can form stable complexes with oseltamivir through dipole-dipole interactions, especially the hydrogen bonds between the portal oxygen atoms of $\mathrm{CB}[n]$ and the amine hydrogen atoms of oseltamivir drug in which the average hydrogen bond distances are found in the range of 1.935 to $2.693 \AA$. The number of hydrogen bonds and average hydrogen bond distances of $\mathrm{CB}[6], \mathrm{CB}[7], \mathrm{CB}[8]$, and $\mathrm{CB}[9]$ complexes with OST drug with different inclusion orientations are tabulated in Table 1.

\section{Complexation energies}

To comprehend the stability of complexes, the complexation energies $\left(E_{\mathrm{cpx}}\right)$ of the oseltamivir with $\mathrm{CB}[n]$ were calculated. The complexation energies are obtained from the energy difference between the energy of complex and the energies of the isolated $\mathrm{CB}[n]$ as host and free oseltamivir as guest. The complexation energies of the $\mathrm{CB}[6], \mathrm{CB}[7], \mathrm{CB}[8]$, and $\mathrm{CB}[9]$ with oseltamivir in gas phase and water solution computed at the B3LYP/6-31G $(\mathrm{d}, \mathrm{p})$ theoretical level are tabulated in Table 1 . The negative values of complexation energies reveal that the host-guest inclusion complexes are exothermic process and the complexes formed are more stable than isolated molecules. The complexation energies of all complexes formed in gas phase are found to be in the range of -7.39 to $-19.83 \mathrm{kcal} / \mathrm{mol}$. The formation of energy for the CB[7]/OST-e complex has the most energetically favorable value of $-19.83 \mathrm{kcal} / \mathrm{mol}$ 
among the inclusion complexes. The complexation abilities of $\mathrm{CB}[n]$ to oseltamivir drug in gas phase are in the order: $\mathrm{CB}[7] / \mathrm{OST}-\mathrm{e}(-19.83 \mathrm{kcal} / \mathrm{mol}) \approx \mathrm{CB}[6] / \mathrm{OST}-\mathrm{p}(-18.69 \mathrm{kcal} / \mathrm{mol}) \approx \mathrm{CB}[8] / \mathrm{OST}-\mathrm{e}(-17.75$ $\mathrm{kcal} / \mathrm{mol})>\mathrm{CB}[7] / \mathrm{OST}-\mathrm{a}(-15.13 \mathrm{kcal} / \mathrm{mol}) \approx \mathrm{CB}[8] / \mathrm{OST}-\mathrm{a}(-14.62 \mathrm{kcal} / \mathrm{mol}) \approx \mathrm{CB}[8] / \mathrm{OST}-\mathrm{p}(-13.63$ $\mathrm{kcal} / \mathrm{mol}) \approx \mathrm{CB}[6] / \mathrm{OST}-\mathrm{a}(-12.58 \mathrm{kcal} / \mathrm{mol}) \approx \mathrm{CB}[9] / \mathrm{OST}(-11.93 \mathrm{kcal} / \mathrm{mol})>\mathrm{CB}[6] / \mathrm{OST}-\mathrm{e}(-9.05$ $\mathrm{kcal} / \mathrm{mol})>\mathrm{CB}[7] / O S T-\mathrm{p}(-7.39 \mathrm{kcal} / \mathrm{mol})$.

The vibrational frequency computations have been carried out at $298.15 \mathrm{~K}$ and $1 \mathrm{~atm}$. Stationary points of the most stable configurations in gas phase i.e., CB[6]/OST-p, CB[7]/OST-e, and CB[8]/OST-e have been fully characterized by vibrational frequency calculations, which also provided zero point vibrational energies (ZPVE) [44]. The standard enthalpy $\left(\Delta \mathrm{H}^{\circ}\right)$ and Gibbs free energy changes $\left(\Delta \mathrm{G}^{\circ}\right)$ of the reactions at $298.15 \mathrm{~K}$ have been derived from the frequency calculations at the B3LYP/6-31G $(d, p)$ theoretical level. The results of frequency calculations display that no imaginary frequencies are observed confirming the $\mathrm{CB}[6] / O S T-p, \mathrm{CB}[7] / O S T-e$, and $\mathrm{CB}[8] / O S T-e$ configurations are the stationary points. The computed ZPVE correction energy changes of complexations between CBs and OST for CB[6]/OST-p, CB[7]/OST-e, and $\mathrm{CB}[8] / \mathrm{OST}-\mathrm{e}$ complexes are found to be $-17.17,-17.62$, and $-15.89 \mathrm{kcal} / \mathrm{mol}$, respectively. The computed enthalpy changes of complexations for CB[6]/OST-p, CB[7]/OST-e, and CB[8]/OST-e complexes are $-15.14,-16.60$, and $-14.62 \mathrm{kcal} / \mathrm{mol}$, respectively. Whereas the computed free energy changes of complexations for CB[6]/OST-p, CB[7]/OST-e, and CB[8]/OST-e complexes are $-5.63,-2.20$, and $-2.90 \mathrm{kcal} / \mathrm{mol}$, respectively.

The negative values of complexation free energy changes indicate that the complexations are occurred via a spontaneous process. In which the negative values of complexation energies and enthalpy changes imply that the complexations are exothermic process and the formed complexes are stable in gas phase which corresponding to the previous report [45]. The complexation energies of all complexes formed in water solution are found to be in the range of -4.70 to $-10.04 \mathrm{kcal} / \mathrm{mol}$. This means that complexations are also found to be exothermic process and the complexes formed are also stable in water solution as same as in the gas phase.

\section{Charge and electronic properties}

Upon the complexation of oseltamivir drug with $\mathrm{CB}[n] \mathrm{s}$, the effect of oseltamivir drug on electronic behavior of $\mathrm{CB}[n] \mathrm{s}$ was investigated to describe the change of their electronic structures. For more understanding the chemical activity of $\mathrm{CB}[n] \mathrm{s}$ to oseltamivir, the highest occupied molecular orbital (HOMO), the lowest unoccupied molecular orbital (LUMO), and energy gap ( $\left.E_{\text {gap }}\right)$ were calculated. The electronic properties of the $\mathrm{CB}[n]$ s comparing with theirs complexes with oseltamivir could be used to evaluate the chemical activity of $\mathrm{CB}[n] \mathrm{s}$ and theirs complexes. The calculated HOMO and LUMO energies and energy gaps of $\mathrm{CB}[n]$ s and theirs complexes with oseltamivir drug are listed in Table 2 . The results show that the energy gaps of $\mathrm{CB}[6], \mathrm{CB}[7], \mathrm{CB}[8]$, and $\mathrm{CB}[9]$ are 7.228, 7.237, 7.224, and 7.207 eV, respectively, these results are found to be consistent with the previous reports $[16,25]$. For the $\mathrm{CB}[n] / \mathrm{OST}$ complexes, the energy gaps of $\mathrm{CB}[6] / \mathrm{OST}, \mathrm{CB}[7] / \mathrm{OST}$, and $\mathrm{CB}[8] / \mathrm{OST}$ complexes are calculated to be in the range of $4.355-5.133,4.527-4.944$, and $4.662-5.024 \mathrm{eV}$, respectively. While the energy gap of a 
$\mathrm{CB}[9] / O S T$ complex is found to be $4.759 \mathrm{eV}$. The decrease in energy gaps of CBs when CB complexation with the drug is found to be in good agreement with the previous works [25].

These deceasing of energy gaps of $\mathrm{CB}[n] \mathrm{s}$ appeared after complexation with oseltamivir drug may be due to the electrons are transferred from $\mathrm{CB}[n] \mathrm{s}$ to oseltamivir drug which confirmed by the charge transfer analysis. The results point out that all of $\mathrm{CB}[n] \mathrm{s}$ are changed in their electrical conductivities due to oseltamivir complexation.

In addition, the quantum molecular descriptions such as electronic chemical potential $(\mu)$, electronegativity $(\chi)$, chemical hardness $(\eta)$, electrophilicity $(\omega)$, and chemical softness $(S)$ of the $\mathrm{CB}[n]$ and their complexation with oseltamivir molecule have been analyzed (Table 2), which were calculated from HOMO and LUMO energy levels (Eq. (2) - (6)). The $\mu, \chi, \eta, \omega$, and $S$ could be considered as the first and the second partial derivatives of electronic energy $(E)$ with respect to the number of electrons $(N)$ at a fixed external potential $(u(r))$ [46]. According to the Janak's approximation [47], analytical and operational definitions of the quantum molecular descriptions were given as follows:

$\mu==\left(E_{\mathrm{LUMO}}+E_{\mathrm{HOMO}}\right) / 2(2)$

$\chi=-\mu(3)$

$\eta==\left(E_{\mathrm{LUMO}}-E_{\mathrm{HOMO}}\right) / 2(4)$

$\omega=(5)$

$S=(6)$

The quantum molecular descriptions can be used to describe the electron transfer between donor and acceptor molecules and supplies data about the structural stability and reactivity of complexes. The increasing of chemical potential and chemical hardness results in the decrease electronegativity, electrophilicity, and chemical softness which induce the increasing of the stability and decreasing of the reactivity. The global indices of stability and reactivity in both gas and water phases are listed in Table 2 . All of values of hardness, chemical potential, electronegativity, electrophilicity, and chemical softness for complexes are modified from the individual $\mathrm{CB}[n]$ s and oseltamivir molecule.

Due to the chemical softness values of $\mathrm{CB}[n] / O S T$ complexes are found higher than the bare $\mathrm{CB}[n] \mathrm{s}$, thus the reactivity of $\mathrm{CB}[n] / O S T$ complexes are higher than the bare $\mathrm{CB}[n] \mathrm{s}$. Inspections of calculated data display that the electronic chemical potential values of all complexes are in the range of -2.991 to $2.297 \mathrm{eV}$, the electronegativity values are in the range of 2.297 to $2.991 \mathrm{eV}$, and the chemical hardness values are in range of 2.178 to $2.566 \mathrm{eV}$. The electrophilicity values are found in range of 1.107 to 1.815 $\mathrm{eV}$ and the chemical softness values are in range of 0.195 to $0.230 \mathrm{eV}$. Suggesting that when oseltamivir forms complexes with $\mathrm{CB}[n]$, the chemical hardness and electronegativity values of complexes are decreased, excepted the electronegativity value of $\mathrm{CB}[6] / O S T-p$ is increased. The values of the chemical potential, electrophilicity, and softness will be increased, excepted the chemical potential value of 
$\mathrm{CB}[6] / O S T-p$, the electrophilicity values of $\mathrm{CB}[8] / O S T-e$ and $\mathrm{CB}[9] / O S T$ are decreased. Thus the results confirm that $\mathrm{CB}[n]$ s are changed in their electrical conductivity due to oseltamivir complexation.

In water phase, the calculated data display that the electronic chemical potential values of all complexes are in the range of -3.769 to $-3.524 \mathrm{eV}$, the electronegativity values are in the range of 3.524 to $3.769 \mathrm{eV}$, and the chemical hardness values are in range of 2.435 to $2.694 \mathrm{eV}$. The electrophilicity values are found in range of 2.323 to $2.781 \mathrm{eV}$ and the chemical softness values are in range of 0.186 to $0.205 \mathrm{eV}$. Suggesting that when oseltamivir forms complexes with $\mathrm{CB}[n]$, the electronic chemical potential and chemical hardness values of complexes are decreased while the values of the electronegativity, electrophilicity, and softness will be increased. Thus, the results confirm that after oseltamivir complexes with $\mathrm{CB}[n]$, the stability of the $\mathrm{CB}[n] /$ OST complexes are lower than the bare $\mathrm{CB}[n] \mathrm{s}$, while the chemical reactivity of the $\mathrm{CB}[n] / O S T$ complexes are higher than the bare $\mathrm{CB}[n] \mathrm{s}$. The results confirm that $\mathrm{CB}[n] \mathrm{s}$ are changed in their electrical conductivity due to oseltamivir complexation.

In summarize here, it was also found that, the values of the energy gaps, electronegativity, chemical hardness, and electrophilicity of bare $\mathrm{CB}[n]$ s and $\mathrm{CB}[n] /$ OST complexes in the gas phase are lower than in the water phase. In the other hand, the values of electronic chemical potential and softness of bare $\mathrm{CB}[n] \mathrm{s}$ and $\mathrm{CB}[n] /$ OST complexes in the gas phase are higher than in the water phase.

One of the essential characteristics disturbing the possible complexation interaction between the host and guest is partial charge transfer. The transferring of electrons has been determined by natural bond orbital analysis before and after oseltamivir complexations with cucurbiturils. The PCT was defined as $Q_{\mathrm{CB}[n] / O S T}-Q_{\mathrm{OST}}$, where the $Q_{\mathrm{CB}[n] / O S T}$ is the total charge of oseltamivir complexation with $\mathrm{CB}[n]$, and the $Q_{O S T}$ is the charge of isolated oseltamivir. Considering the PCT of oseltamivir complexation, the positive value of PCT represents the electron transfer from oseltamivir molecule to $\mathrm{CB}[n]$; negative value of PCT means the opposite procedure. The computed PCTs of $\mathrm{CB}[n] / O S T$ complexes are found in the range of 0.022 to -0.042 e. The computed PCT results confirm that the charge transfer takes place from the $\mathrm{CB}[n] \mathrm{s}$ to the oseltamivir. This means that when the $\mathrm{CB}[n]$ molecules interacted with oseltamivir, theirs charge distributions are modified.

The orbital distributions have been performed to analyze electronic property modification of $\mathrm{CB}[n] \mathrm{s}$ corresponding to the complexation with oseltamivir drug. The HOMO and the LUMO distributions of the $\mathrm{CB}[6], \mathrm{CB}[7], \mathrm{CB}[8]$, and $\mathrm{CB}[9]$, and their complexes with oseltamivir are plotted and displayed in Figs. 7 and 8 . For the bare $\mathrm{CB}[n] \mathrm{s}$, all of the $\mathrm{HOMO}$ and the $\mathrm{LUMO}$ orbitals display charge delocalization on the $\mathrm{CB}[n] \mathrm{s}$. While, all of the HOMO and the LUMO orbitals of $\mathrm{CB}[n] / O S T$ complexes are delocalized on oseltamivir drug. This means that after the bare $\mathrm{CB}[n]$ s complexed with oseltamivir drug, their $\mathrm{HOMO}$ and the LUMO orbitals are clearly redistributed or changed. These approve the significant modifications in the electronic structures of $\mathrm{CB}[n]$ s by oseltamivir drug complexation.

The chemical reactivities of molecules can be also associated with their electrostatic potentials and therefore, the molecular electrostatic potentials (MEP) are extensively used to identify electrophilic and 
nucleophilic areas of molecules in electrostatic interactions. In order to identify the MEP contours of the bare $\mathrm{CB}[n] \mathrm{s}$ (Fig. 9) and the most stable CB7]/OST-e complex (Fig. 10), the MEP surfaces are defined based on electron density and represented by a RGB color model, in which red regions are more negative charge and blue regions are more positive charge. Based on Fig. 9, it is seen that the negative charges are localized over the portal oxygen atom on $\mathrm{CB}[n]$ s. Based on Fig. 10, after the $\mathrm{CB}[7]$ complexed with oseltamivir drug, the red regions of portal oxygen atom on $\mathrm{CB}[7]$ are decreased. Imply that the charge transfer takes place from the $\mathrm{CB}[7]$ to the oseltamivir drug which corresponds to the PCT values approving the host-guest, oseltamivir- $\mathrm{CB}[n]$ complex interaction.

\section{Conclusions}

The DFT B3LYP/6-31G $(\mathrm{d}, \mathrm{p})$ optimized structures of cucurbit[n]urils $n=6-9$ are found to posses a $\mathrm{D}_{n h}$ symmetry. The formation of host-guest complexes of $\mathrm{CB}[n]-\mathrm{OST}$ are proper in $\mathrm{CB}[n]$ cavity of, except for $\mathrm{CB}[6] / O S T-a, C B[6] / O S T-p$ and CB[8]/OST-p complexes, oseltamivir drug is expelled out of the cavity.

The intermolecular interactions in all $\mathrm{CB}[n] /$ OST complexes occurring via a large number of dipole-dipole interactions, especially the hydrogen bonds between the portal oxygen atom of $\mathrm{CB}[n]$ and the hydrogen atom of amine group of oseltamivir drug. The negative complexation energy values of $\mathrm{CB}[n] / \mathrm{OST}$ complexes in both gas and water phases are indicated that the host-guest complexes are exothermic process and the complexes are more stable than bare $\mathrm{CB}[n]$. In addition, the $\mathrm{CB}[7] / O S T$ complex is more stable than that of all studied $\mathrm{CB}[n] / O S T$ complexes. The frequency calculation results of the most stable complexes for each of CBs indicate that complexations are occurred via a spontaneous process. The NBO calculations and MEP plots indicate that the host-guest complexes attend with charge transfer from the $\mathrm{CB}[n]$ host to the oseltamivir guest. In addition, after oseltamivir drug complexation the HOMO and LUMO orbitals and the energy gaps of $\mathrm{CB}[n]$ are also clearly modified. All of the calculated complexation properties point out here that $\mathrm{CB}[n]$ can act as a host for appropriately oseltamivir guest, even in aqueous solution.

\section{Declarations}

Funding This research project was financially supported by Mahasarakham University 2021, Thailand.

Conflicts of interest/Competing interests The authors declare no conflicts of interest/competing interests.

Availability of data and material Not applicable (All data generated or analyzed during this study are included in this published article).

Code availability Not applicable.

Authors' contributions W. Rakrai and B. Wanno contributed to the study conception and design. The DFT calculations were performed by W. Rakrai, C. Tabtimsai, and B. Wanno. The data analysis and the first draft of the manuscript were made by W. Rakrai, and B. Wanno. 
Revising the manuscript critically for important intellectual content on subsequent versions of the manuscript has done by W. Rakrai, C. Kaewtong, and B. Wanno. All the authors read and approved the final manuscript.

Ethics approval The ethical standards have been met.

Consent for publication All co-authors have seen and approved the manuscript.

\section{References}

1. Webber MJ, Langer R (2017) Chem Soc Rev 46:6600-6620

2. Miskolczy Z, Megyesi M, Tarkanyi G, Mizsei R, Biczok L (2011) Org Biomol Chem 9:1061-1070

3. Cong H, Li CR, Xue SF, Tao Z, Zhub QJ, Wei G (2011) Org Biomol Chem 9:1041-1046

4. Krause-Heuer AM, Grant MP, Orkey N, Aldrich-Wright JR (2008) Aust J Chem 61:675-681

5. Kemp S, Wheate NJ, Wang S, Collins JG, Ralph SF, Day Al, Higgins VJ, Aldrich-Wright JR (2007) J Biol Inorg Chem 12:969-979

6. Zhang J, Ma PX. (2013) Adv Drug Deliv Rev 65:1215-1233

7. Bani-Yaseen AD, Mo'ala A (2014) Spectrochim Acta A 131:424-431

8. Gallego-Yerga L, de la Torre C, Sansone F, Casnati A, Mellet CO, García Fernandez' JM, Cena V (2021) Carbohydr Polym 252:117135

9. Wang J, Ding X, Guo X (2019) Adv Colloid Interface Sci 269:187-202

10. Basilotta R, Mannino D, Filippone A, Casili G, Prestifilippo A, Colarossi L, Raciti G, Esposito E, Campolo M (2021) Molecules 26:3963

11. Muzzalupo R, Nicoletta FP, Trombino S, Cassano R, lemma F, Picci (2007) Colloids Surf B 58:197202

12. Kemp S, Wheate NJ, Stootman FH, Aldrich-Wright JR (2007) Supramol Chem 19:475-484

13. Shchepotina E.G, Pashkina EA, Yakushenko EV, Kozlov VA (2011) Nanotechnol Russ 6:773-779

14. Walker S, Oun R, Mclnnes FJ, Wheate NJ (2011) Isr J Chem 51:616-624

15. Wheate NJ, Limantoro C (2016) Supramol Chem 28:849-856

16. Suvitha A, Venkataramanan NS, Mizuseki H, Kawazoe Y, Ohuchi N (2010) J Incl Phenom Macrocycl Chem 66:213-218

17. Behrend R, Meyer E, Rusche F (1905) Justus Liebigs Ann Chem 339:1-37

18. Freeman WA, Mock WL, Shih NY (1981) J Am Chem Soc 103:7367-7368

19. Kim J, Jung I-S, Kim S-Y, Lee E, Kang J-K, Sakamoto S, Yamaguch, K, Kim K (2000) J Am Chem Soc 122:540-541

20. Uzunova VD, Cullinane C, Brix K, Nau WM, Day Al (2010) Org Biomol Chem 8: 2037-2042 
21. Zhao Y, Buck DP, Morris DL, Pourgholami MH, Day Al, Collins JG (2008) Org Biomol Chem 6:45094515

22. Wheate NJ (2008) J Inorg Biochem 102:2060-2066

23. Corda E, Hernandez M, Sanchez-Cortes S, Sevilla P (2018) Colloids Surf A: Physicochem Eng Asp 557:66-75

24. Jeon YJ, Kim S-Y, Ko YH, Sakamoto S, Yamaguchi K, Kim K (2005) Org Biomol Chem 3:2122-2125

25. Nojini ZB, Yavari F, Bagherifar S (2012) J Mol Liq 166:53-61

26. Sabet M, Ganji MD (2013) J Mol Model 19:4013-4023

27. Assaf KI, Nau WM (2015) Chem Soc Rev 44:394-418

28. Gurbuz S, Idris M, Tuncel D (2015) Org Biomol Chem 13:330-347

29. Kim K, Selvapalam N, Ko YH, Park KM, Kim D, Kim J (2007) Chem Soc Rev 36:267-279

30. Hayden F, Treanor JJ, Fritz RS, Lobo M, Betts RF, Miller M, Kinnersley N, Mills RG, Ward P, Straus SE (1999) Jama 282:1240-1246

31. Lindemann L, Jacobsen H, Schuhbauer D, Knoflach F, Gatti S, Wettstein JG, Loetscher H, Chu T, Ebeling M, Paulson JC, Prinssen E, Brockhaus M (2010) Eur J Pharmacol 628:6-10

32. Bartels P, von Tumpling W (2008) Sci Total Environ 405:215-225

33. Accinelli C, Caracciolo, AB, Grenni P (2007) Int J Environ Anal Chem 87:579-587

34. Sacca ML, Accinelli C, Fick J, Lindberg R, Olsen B (2009) Chemosphere 75:28-33

35. Pinjari RV, Khedkar JK, Gejji SP (2010) J Incl Phenom Macrocycl Chem 66:371-380

36. Becke AD (1988) Phys Rev A 38:3098-3100

37. Becke AD (1993) J Chem Phys 98:5648-5652

38. Lee C, Yang W, Parr RG (1988) Phys Rev B 37:785-789

39. Frisch MJ, Trucks GW, Schlegel HB, Scuseria GE, Robb MA, Cheeseman JR, Scalmani G, Barone V, Mennucci B, Petersson GA, Nakatsuji , Caricato M, Li X, Hratchian HP, Izmaylov AF, Bloino J, Zheng G, Sonnenberg JL, Hada M, Ehara M, Toyota K, Fukuda R, Hasegawa J, Ishida M, Nakajima T, Honda Y, Kitao O, Nakai H, Vreven T, Montgomery JA, Peralta JrJE, Ogliaro F, Bearpark M, Heyd JJ, Brothers E, Kudin KN, Staroverov VN, Kobayashi R, Normand J, Raghavachari K, Rendell A, Burant JC, lyengar SS, Tomasi J, Cossi M, Rega N, Millam JM, Klene M, Knox JE, Cross JB, Bakken V, Adamo C, Jaramillo J, Gomperts R, Stratmann RE, Yazyev O, Austin AJ, Cammi R, Pomelli C, Ochterski JW, Martin RL, Morokuma K, Zakrzewski VG, Voth GA, Salvador P, Dannenberg JJ, Dapprich S, Daniels AD, Farkas Ö, Foresman JB, Ortiz JV, Cioslowski J, Fox DJ (2009) GAUSSIAN 09, Revision A.02, Gaussian Inc, Wallingford CT,.

40. Barone V, Cossi M, Tomasi J (1998) J Comput Chem 19:404-417

41. Cossi M, Barone V (1998) J Chem Phys 109:6246-6254

42. Flükiger P, Lüthi HP, Portmann S (2000) MOLEKEL 4.3, Swiss center for scientific computing, Manno, Switzerland 
43. Pichierri F (2006) J Mol Struct (Theochem) 765:151-152

44. Ochterski JW, Thermochemistry in Gaussian, Gaussian Inc., Pittsburgh, PA, 2000.

45. Safia H, Fatiha M, Belgacem B, Leila N (2020) J Mol Struct 1217:128390

46. Parr RG, Donelly RA, Levy M, Palke WE (1978) J Chem Phys 68:3801-3807

47. Janak JF (1978) Phys Rev B 18 7165-7168

\section{Tables}

Table 1 The complexation energies $\left(E_{\mathrm{cpx}}\right)$ in gas and water phase (in parenthesis), partial charge transfers (PCTs), average hydrogen bond distances (HBD), and number of hydrogen bond (HB) of $\mathrm{CB}[n] / \mathrm{OST}$ complexes obtained from the B3LYP/6-31G(d,p) theoretical level. 


\begin{tabular}{|c|c|c|c|c|}
\hline Complexes & $E_{\mathrm{cpx}}^{\mathrm{a}}$ & $\mathrm{PCT}^{\mathrm{b}}$ & Average $\mathrm{HBD}^{\mathrm{c}}$ & Number of HB \\
\hline \multirow[t]{2}{*}{ [CB6]/OST-e } & $-9.05(-d)$ & -0.028 & & \\
\hline & & & 2.476 & 2 \\
\hline \multirow[t]{2}{*}{ [CB6]/OST-a } & $-12.58(-4.70)$ & -0.033 & & \\
\hline & & & 2.611 & 4 \\
\hline \multirow[t]{2}{*}{ [CB6]/OST-p } & $-18.69(-10.04)$ & -0.025 & & \\
\hline & & & 2.632 & 2 \\
\hline \multirow[t]{2}{*}{ [CB7]/OST-e } & $-19.83(-7.45)$ & -0.042 & & \\
\hline & & & 2.497 & 3 \\
\hline \multirow[t]{2}{*}{ [CB7]/OST-a } & $-15.13(-6.28)$ & -0.042 & & \\
\hline & & & 2.344 & 4 \\
\hline \multirow[t]{2}{*}{ [CB7]/OST-p } & $-7.39(-d)$ & -0.024 & & \\
\hline & & & 2.058 & 1 \\
\hline \multirow[t]{2}{*}{ [CB8]/OST-e } & $-17.75(-9.77)$ & -0.031 & & \\
\hline & & & 2.693 & 3 \\
\hline \multirow[t]{2}{*}{ [CB8]/OST-a } & $-14.62(-7.73)$ & -0.033 & & \\
\hline & & & 2.586 & 4 \\
\hline \multirow[t]{2}{*}{ [CB8]/OST-p } & $-13.63(-6.01)$ & -0.022 & & \\
\hline & & & 1.935 & 1 \\
\hline \multirow[t]{2}{*}{ [CB9]/OST } & $-11.93(-6.90)$ & -0.031 & & \\
\hline & & & 2.313 & 1 \\
\hline
\end{tabular}

a in kilocalories $/ \mathrm{mol}(\mathrm{kcal} / \mathrm{mol}),{ }^{b}$ in electrons $(e),{ }^{c}$ in angstroms $(\AA),{ }^{d}$ unconvergence.

Table 2 The highest occupied molecular orbital energies $\left(E_{\mathrm{HOMO}}, \mathrm{eV}\right)$, the lowest unoccupied molecular orbital energies $\left(E_{\mathrm{LUMO}}, \mathrm{eV}\right)$, energy gaps $\left(E_{\mathrm{gap}}, \mathrm{eV}\right)$, electronic chemical potential $(m, \mathrm{eV})$, electronegativity $(c, \mathrm{eV})$, chemical hardness $(h, \mathrm{eV})$, electrophilicity $(w, \mathrm{eV})$, and softness $(S, \mathrm{eV})$ of oseltamivir, $\mathrm{CB}[n]$ and $\mathrm{CB}[n] /$ OST complexes obtained in gas and water phases (in parenthesis). 


\begin{tabular}{|c|c|c|c|c|c|c|c|c|}
\hline Type & $E_{\mathrm{HOMO}}$ & $E_{\mathrm{LUMO}}$ & $E_{\text {gap }}$ & $m$ & c & $h$ & $w$ & $s$ \\
\hline \multirow[t]{2}{*}{ OST } & -6.248 & -1.354 & 4.894 & -3.801 & 3.801 & 2.447 & 2.953 & 0.204 \\
\hline & $(-6.504)$ & $(-1.279)$ & $(5.225)$ & $(-3.891)$ & (3.891) & (2.612) & (2.898) & (0.191) \\
\hline \multirow[t]{2}{*}{ CB[6] } & -6.424 & 0.803 & 7.228 & -2.811 & 2.811 & 3.614 & 1.093 & 0.138 \\
\hline & $(-6.694)$ & $(0.626)$ & (7.320) & $(-3.034)$ & (3.034) & (3.660) & (1.258) & $(0.137)$ \\
\hline \multirow[t]{2}{*}{ CB[7] } & -6.507 & 0.730 & 7.237 & -2.888 & 2.888 & 3.619 & 1.153 & 0.138 \\
\hline & $(-6.749)$ & $(0.599)$ & (7.347) & $(-3.075)$ & (3.075) & (3.674) & $(1.287)$ & $(0.136)$ \\
\hline \multirow[t]{2}{*}{$\mathrm{CB}[8]$} & -6.574 & 0.649 & 7.224 & -2.963 & 2.963 & 3.612 & 1.215 & 0.138 \\
\hline & $(-6.803)$ & $(0.571)$ & (7.374) & $(-3.116)$ & (3.116) & (3.687) & $(1.316)$ & $(0.136)$ \\
\hline \multirow[t]{2}{*}{$\mathrm{CB}[9]$} & -6.632 & 0.576 & 7.207 & -3.028 & 3.028 & 3.604 & 1.272 & 0.139 \\
\hline & $(-6.857)$ & $(0.544)$ & (7.402) & $(-3.157)$ & (3.157) & (3.701) & $(1.346)$ & $(0.135)$ \\
\hline \multirow[t]{2}{*}{ CB[6]/OST-e } & -5.244 & -0.111 & 5.133 & -2.677 & 2.677 & 2.566 & 1.396 & 0.195 \\
\hline & $(-6.232)$ & $(-0.844)$ & (5.388) & $(-3.538)$ & (3.538) & $(2.694)$ & (2.323) & $(0.186)$ \\
\hline \multirow[t]{2}{*}{ CB[6]/OST-a } & -4.848 & -0.493 & 4.355 & -2.670 & 2.670 & 2.178 & 1.637 & 0.230 \\
\hline & $(-6.095)$ & $(-1.197)$ & $(4.898)$ & $(-3.646)$ & (3.646) & (2.449) & (2.715) & $(0.204)$ \\
\hline \multirow[t]{2}{*}{ CB[6]/OST-p } & -5.455 & -0.527 & 4.928 & -2.991 & 2.991 & 2.464 & 1.815 & 0.203 \\
\hline & $(-6.395)$ & $(-1.143)$ & $(5.252)$ & $(-3.769)$ & (3.769) & $(2.626)$ & $(2.705)$ & $(0.190)$ \\
\hline \multirow[t]{2}{*}{ CB[7]/OST-e } & -4.843 & 0.073 & 4.917 & -2.385 & 2.385 & 2.458 & 1.157 & 0.203 \\
\hline & $(-6.095)$ & $(-0.952)$ & (5.143) & $(-3.524)$ & (3.524) & $(2.572)$ & (2.415) & $(0.194)$ \\
\hline \multirow[t]{2}{*}{ CB[7]/OST-a } & -4.841 & -0.314 & 4.527 & -2.577 & 2.577 & 2.263 & 1.467 & 0.221 \\
\hline & $(-6.095)$ & $(-1.225)$ & $(4.871)$ & $(-3.660)$ & $(3.660)$ & $(2.435)$ & $(2.750)$ & $(0.205)$ \\
\hline \multirow[t]{2}{*}{ CB[7]/OST-p } & -5.167 & -0.223 & 4.944 & -2.695 & 2.695 & 2.472 & 1.469 & 0.202 \\
\hline & $(-6.313)$ & $(-1.007)$ & (5.306) & $(-3.660)$ & $(3.660)$ & $(2.653)$ & $(2.524)$ & $(0.188)$ \\
\hline \multirow[t]{2}{*}{ CB[8]/OST-e } & -4.679 & 0.085 & 4.765 & -2.297 & 2.297 & 2.382 & 1.107 & 0.210 \\
\hline & $(-6.041)$ & $(-1.170)$ & $(4.871)$ & $(-3.606)$ & (3.606) & $(2.435)$ & $(2.669)$ & $(0.205)$ \\
\hline \multirow[t]{2}{*}{ CB[8]/OST-a } & -4.913 & -0.252 & 4.662 & -2.583 & 2.583 & 2.331 & 1.431 & 0.215 \\
\hline & $(-6.259)$ & $(-1.225)$ & (5.034) & $(-3.742)$ & (3.742) & $(2.517)$ & $(2.781)$ & (0.199) \\
\hline \multirow[t]{2}{*}{ CB[8]/OST-p } & -5.291 & -0.267 & 5.024 & -2.779 & 2.779 & 2.512 & 1.537 & 0.199 \\
\hline & $(-6.340)$ & $(-1.116)$ & $(5.225)$ & $(-3.728)$ & (3.728) & $(2.612)$ & $(2.660)$ & (0.191) \\
\hline
\end{tabular}




$\begin{array}{lllllllll}\mathrm{CB}[9] / \mathrm{OST} & -4.787 & -0.028 & 4.759 & -2.408 & 2.408 & 2.379 & 1.218 & 0.210 \\ & (-6.313) & (-1.143) & (5.170) & (-3.728) & (3.728) & (2.585) & (2.688) & (0.193)\end{array}$

Figures

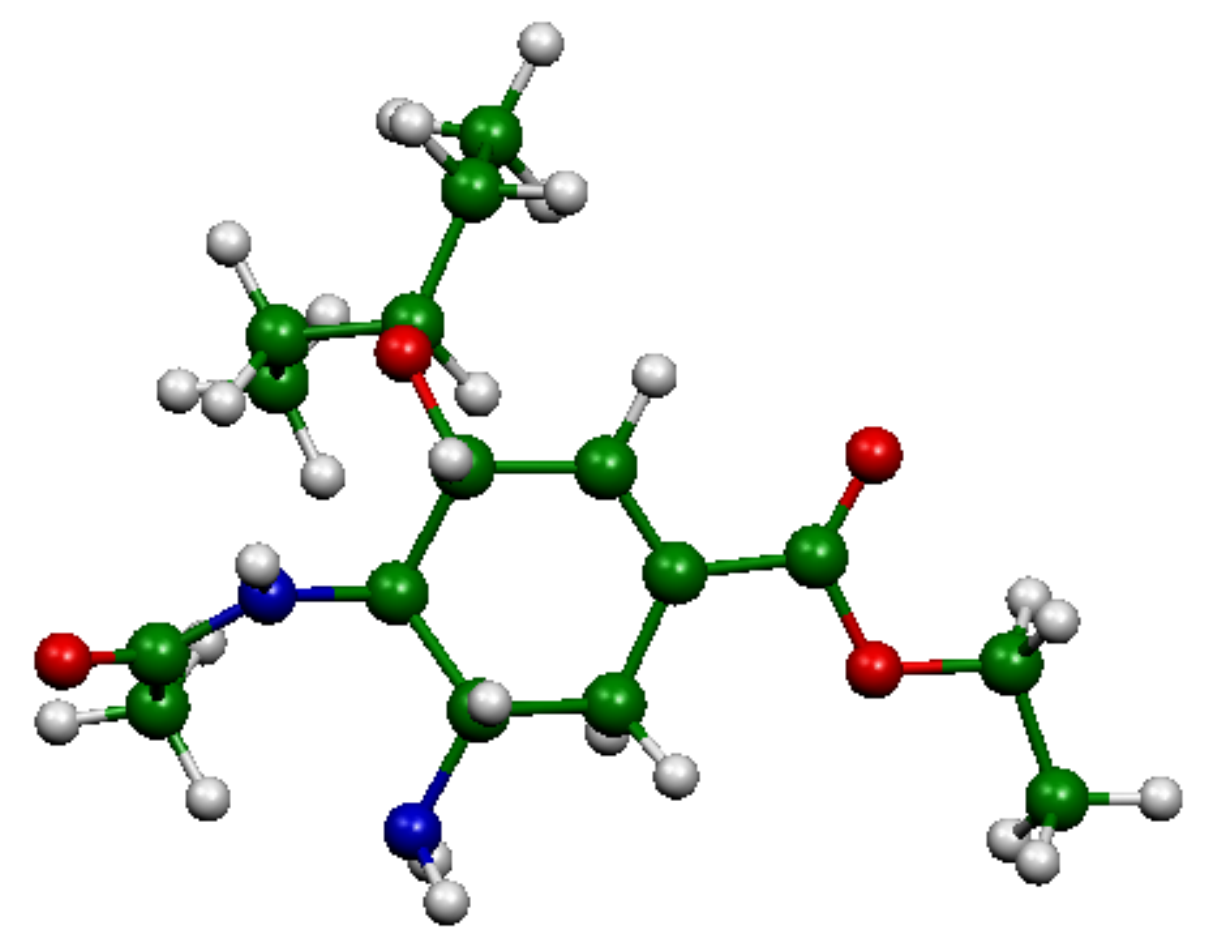

Figure 1

Optimized structure of oseltamivir
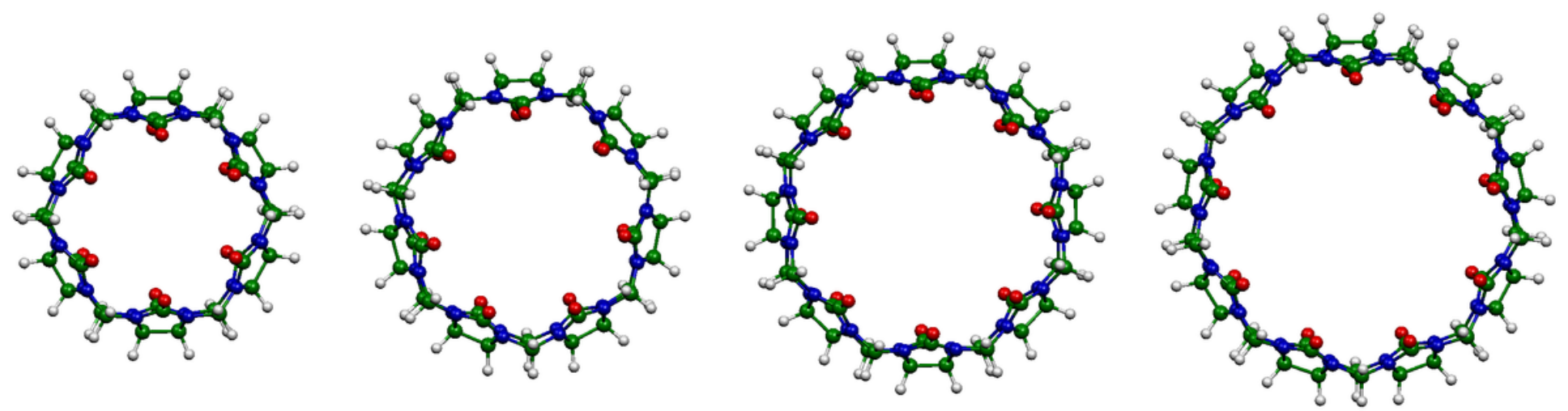

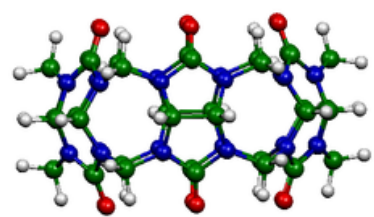

(a)

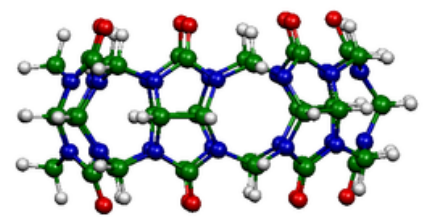

(b)

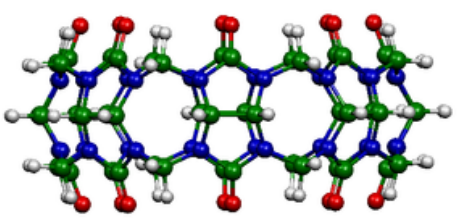

(c)

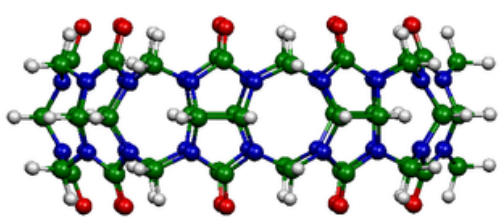

(d) 
Figure 2

Optimized structures of (a) CB[6], (b) CB[7], (c) CB[8] and (d) CB[9]
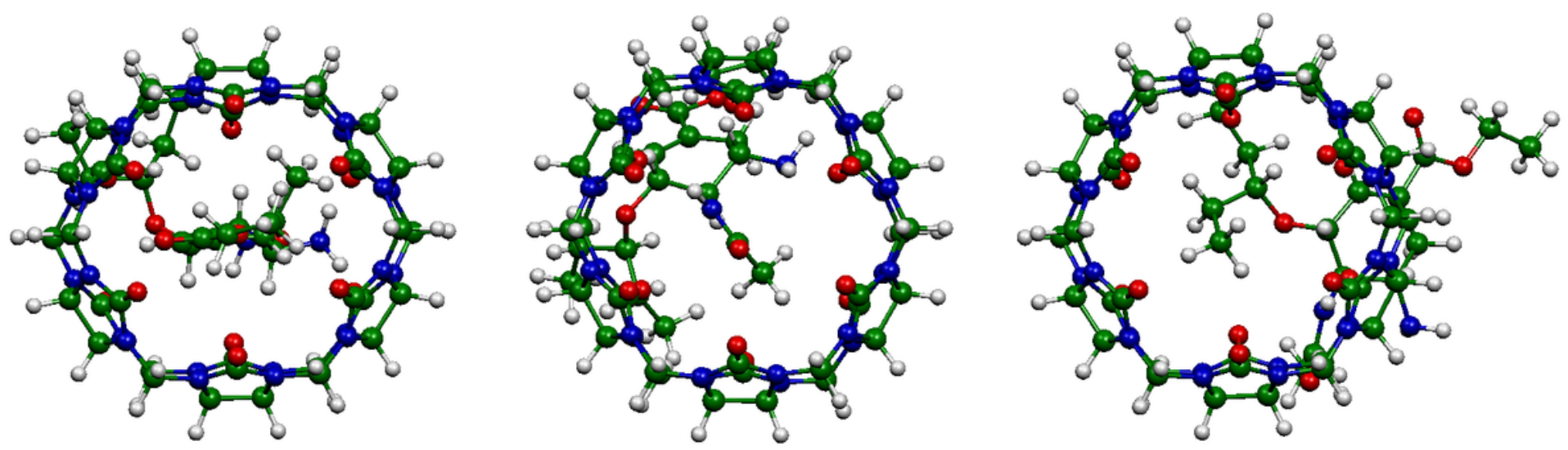

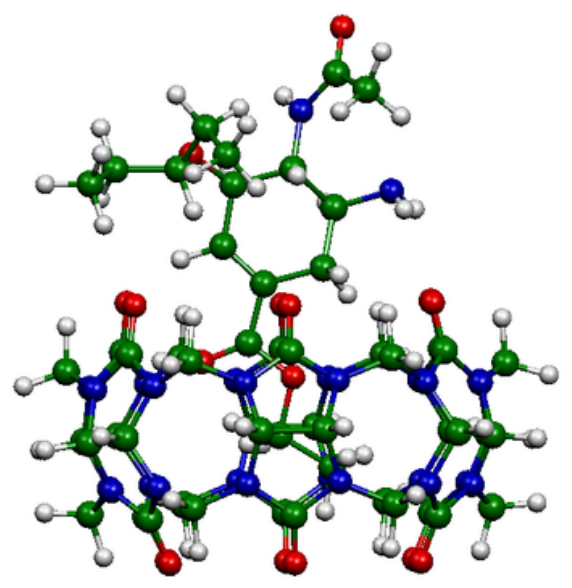

(a)

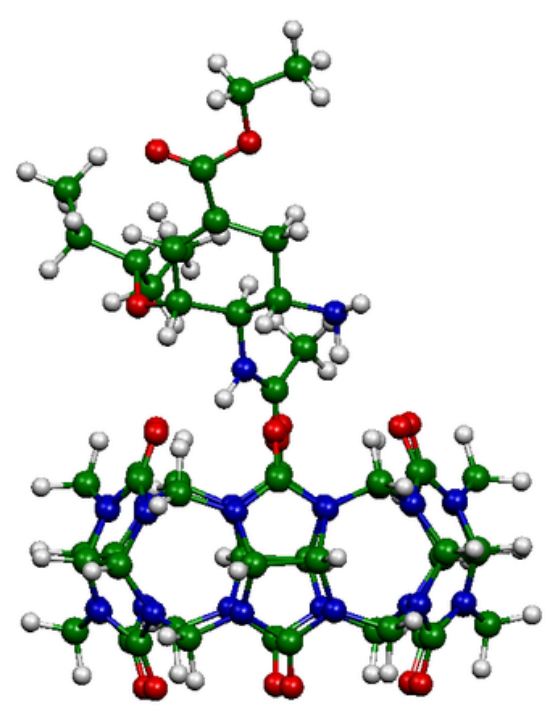

(b)

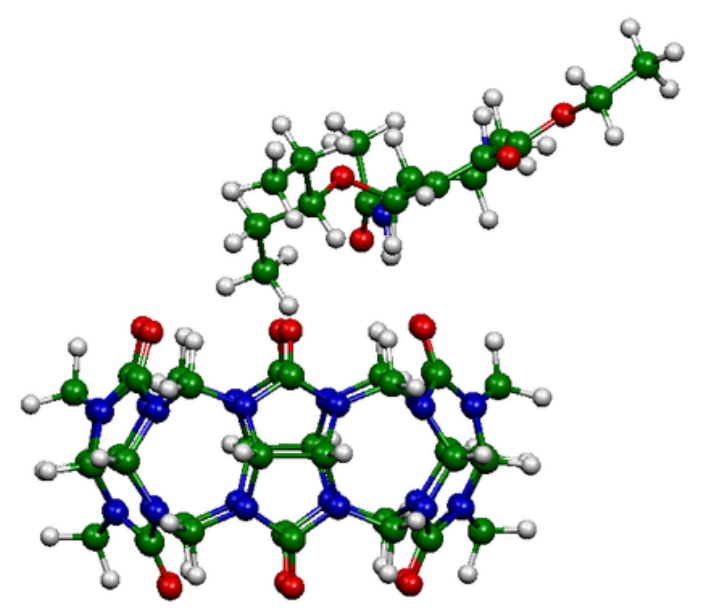

(c)

Figure 3

Optimized structures of (a) CB[6]/OST-e, (b) CB[6]/OST-a, and (c) CB[6]/OST-p complexes. Birds eyeview (top) and side view (bottom) 

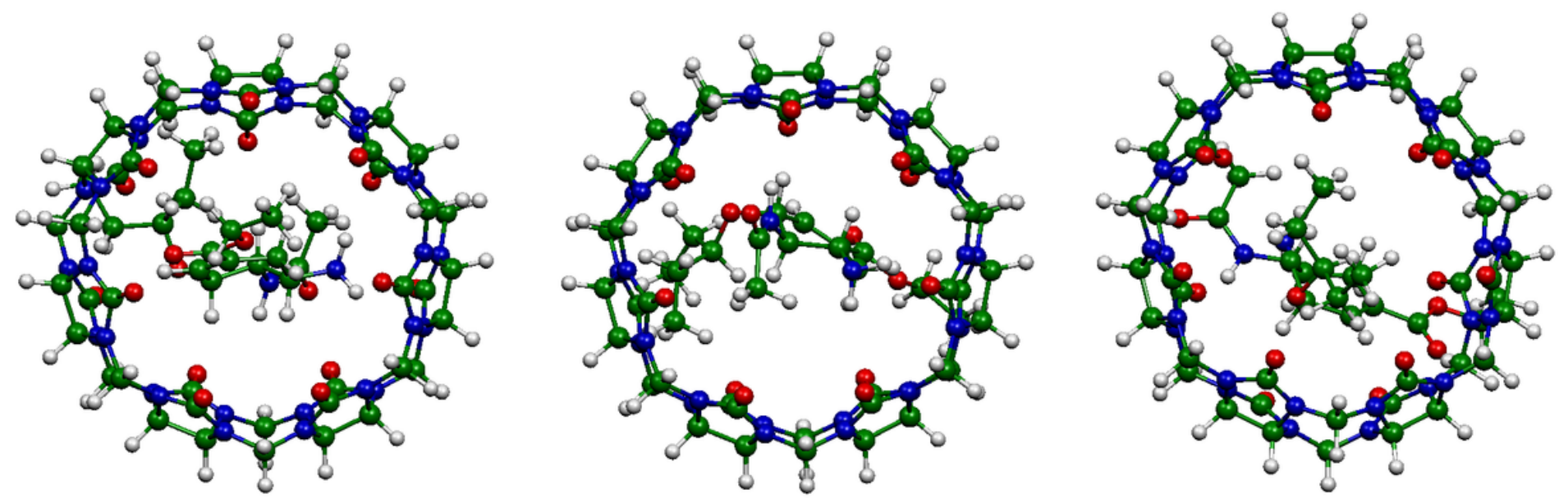

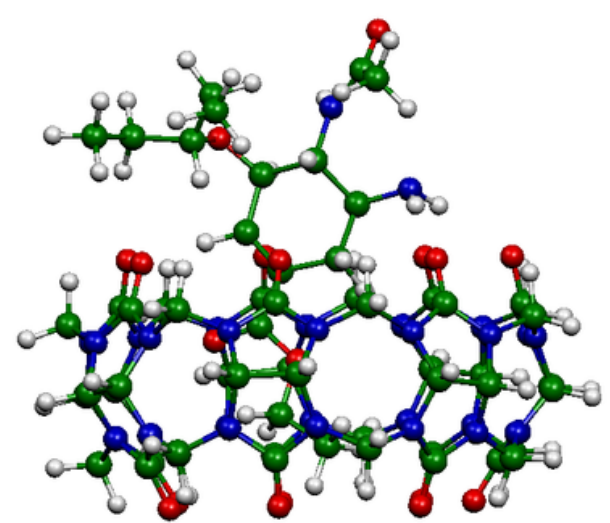

(a)

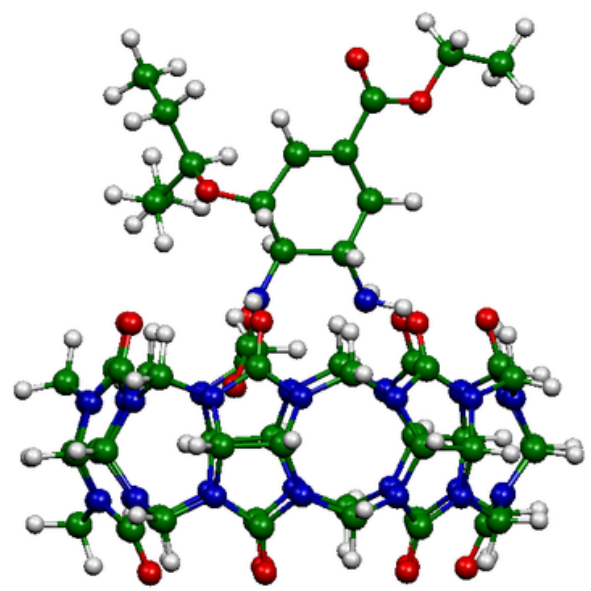

(b)

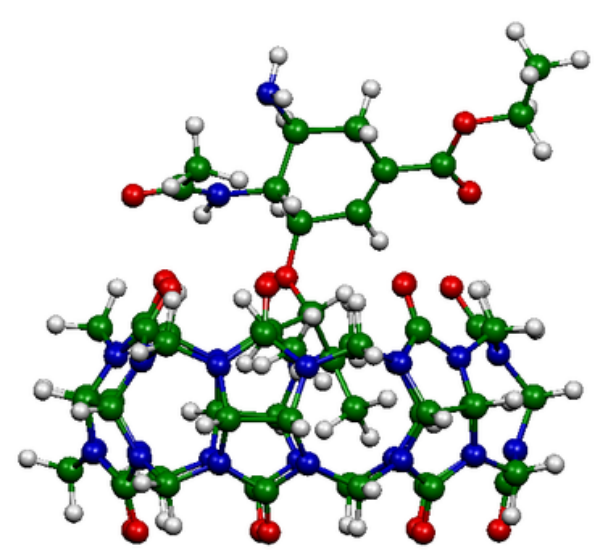

(c)

Figure 4

Optimized structures of (a) CB[7]/OST-e, (b) CB[7]/OST-a, and (c) CB[7]/OST-p complexes. Birds eyeview (top) and side view (bottom) 

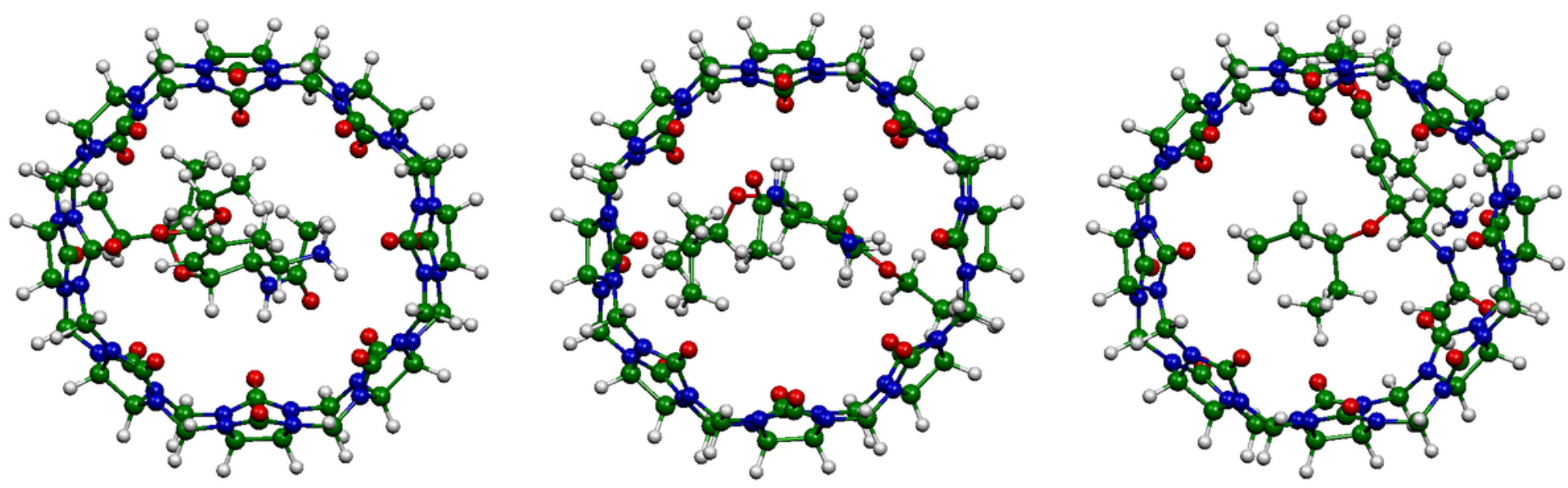

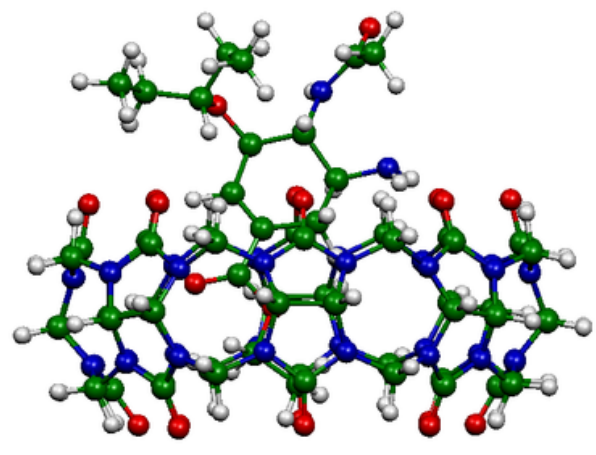

(a)

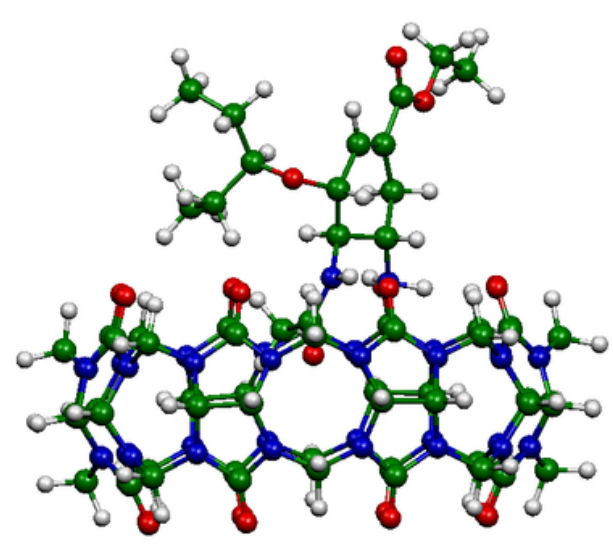

(b)

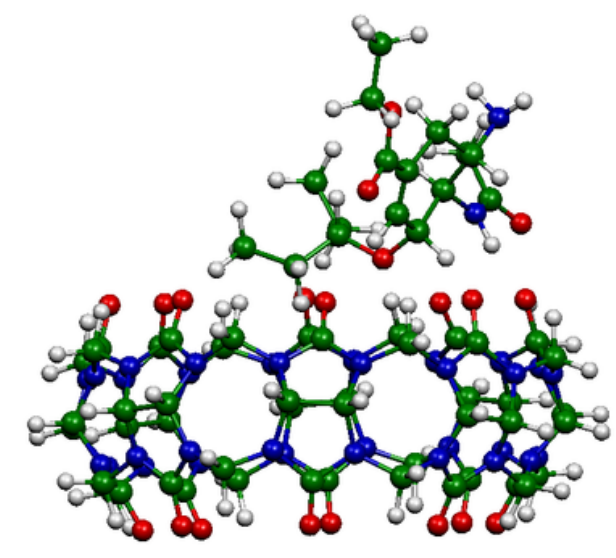

(c)

Figure 5

Optimized structures of (a) CB[8]/OST-e, (b) CB[8]/OST-a, and (c) CB[8]/OST-p complexes. Birds eyeview (top) and side view (bottom) 

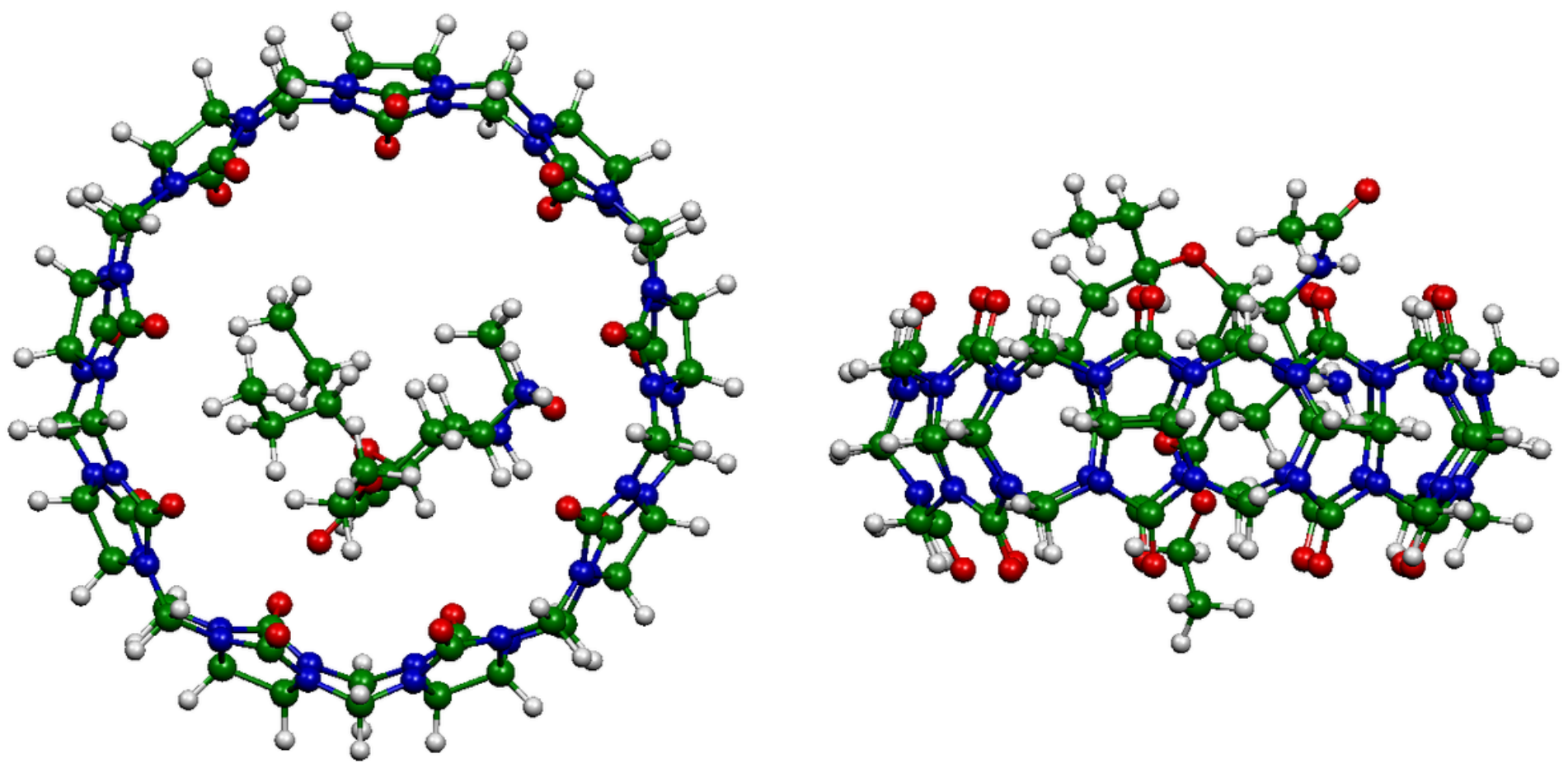

Figure 6

Optimized structures of CB[9]/OST complex, birds eye-view (left) and side view (right) 

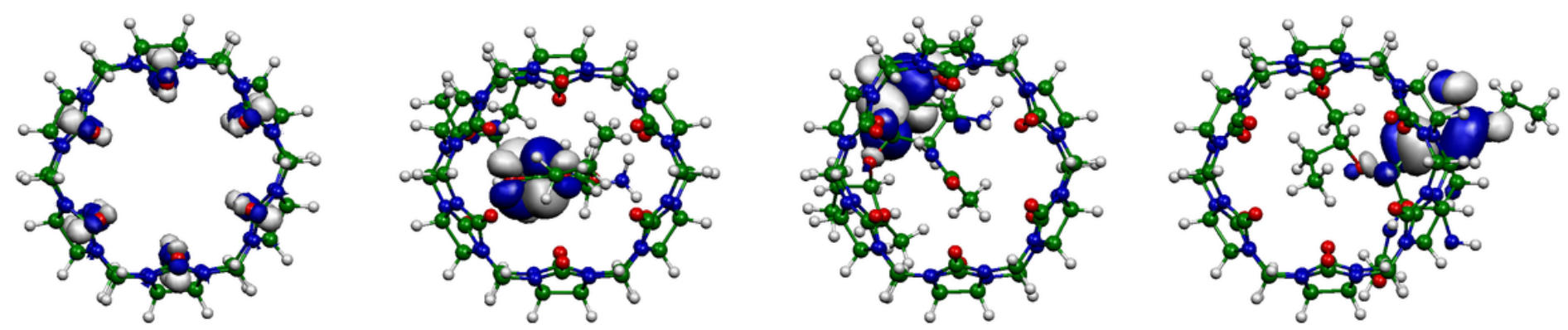

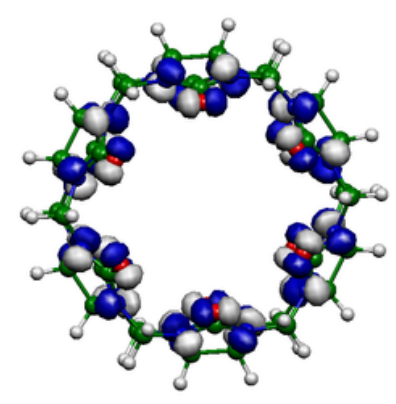

(a)
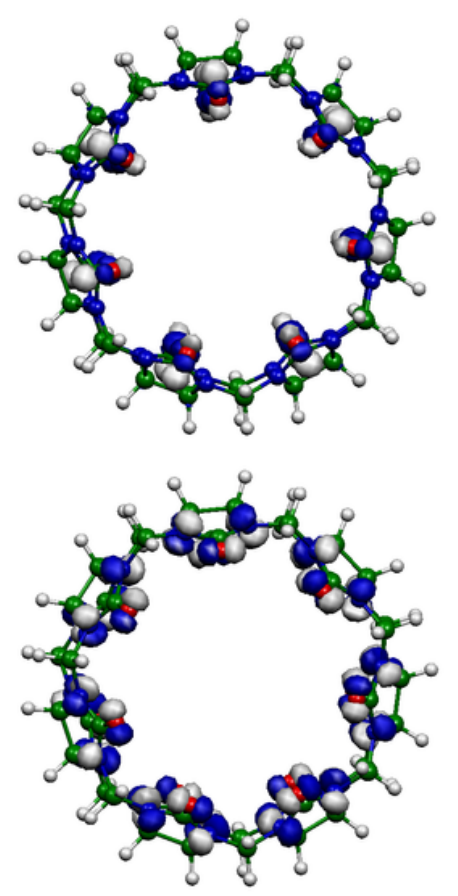

(e)

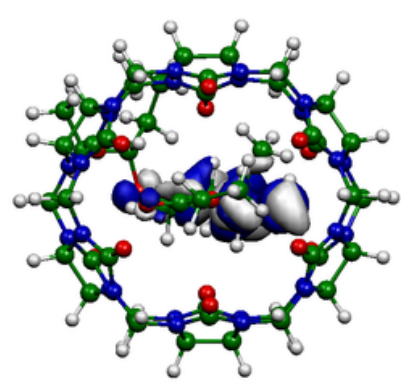

(b)

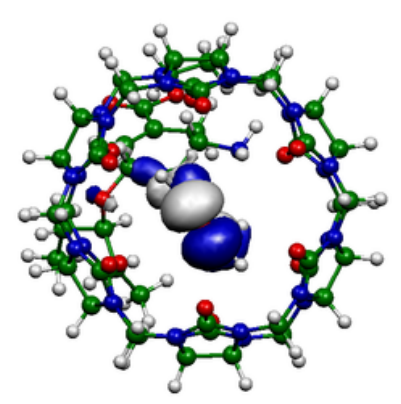

(c)

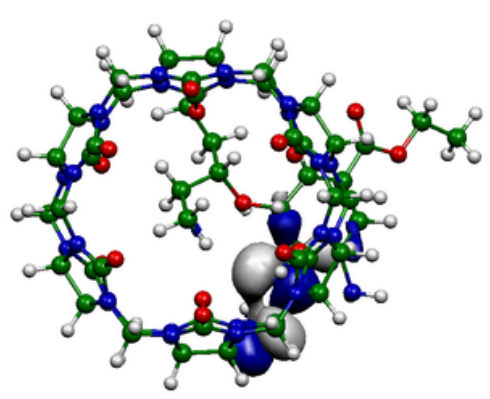

(d)
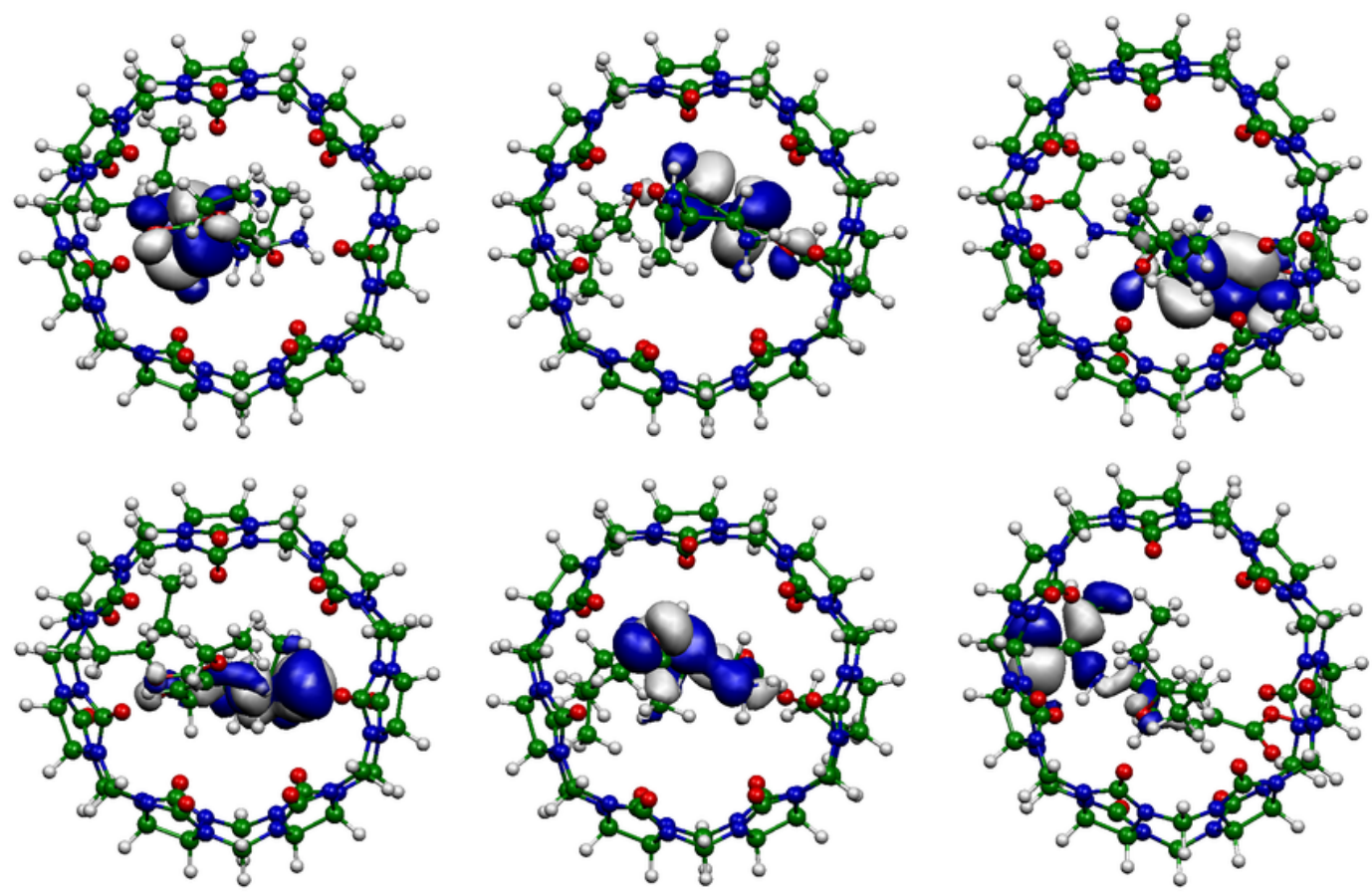

(f)

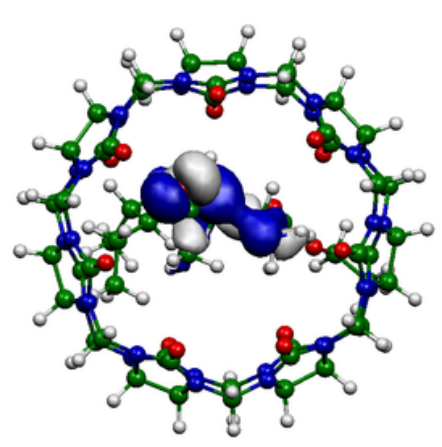

(g)

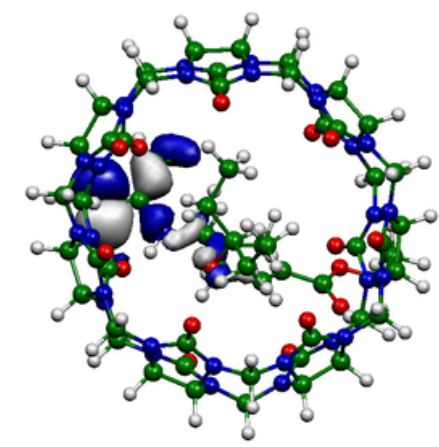

(h)

Figure 7

Plots of the LUMO (top) and the HOMO (bottom) orbitals of (a) CB[6], (b) CB[6]/OST-e, (c) CB[6]/OST-a, (d) CB[6]/OST-p, (e) CB[7], (f) CB[7]/OST-e, (g) CB[7]/OST-a, and (h) CB[7]/OST-p 

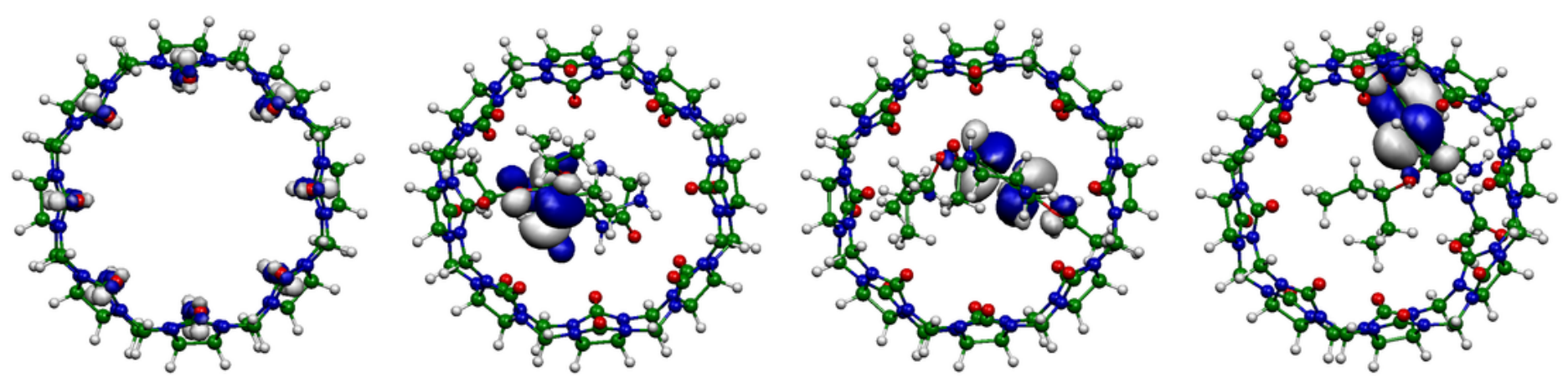

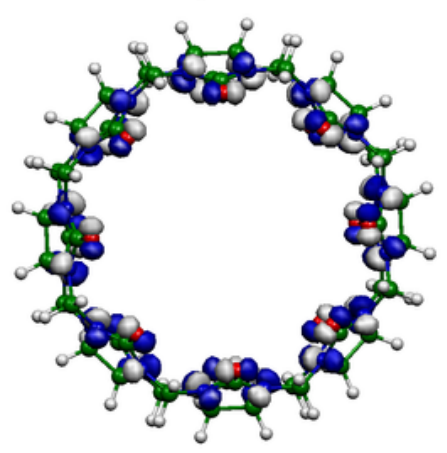

(a)

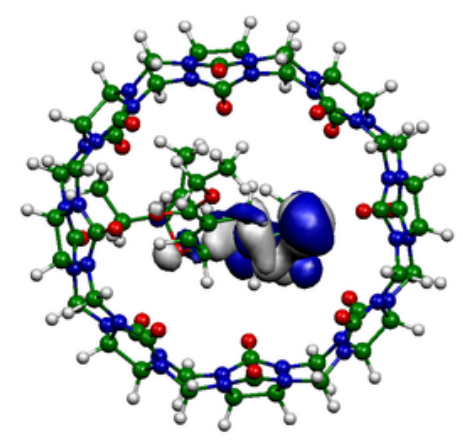

(b)

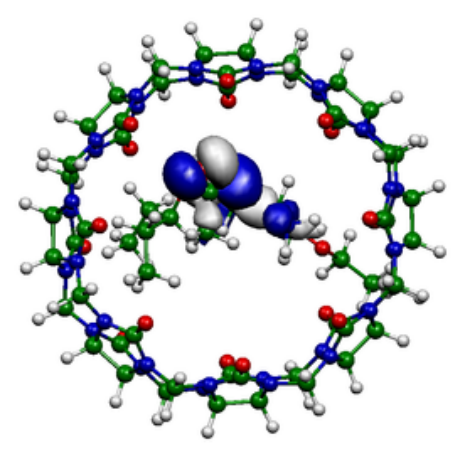

(c)

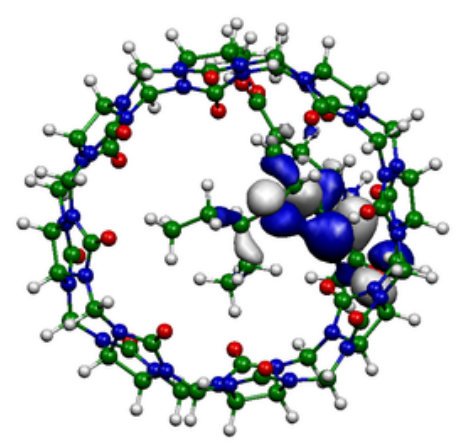

(d)
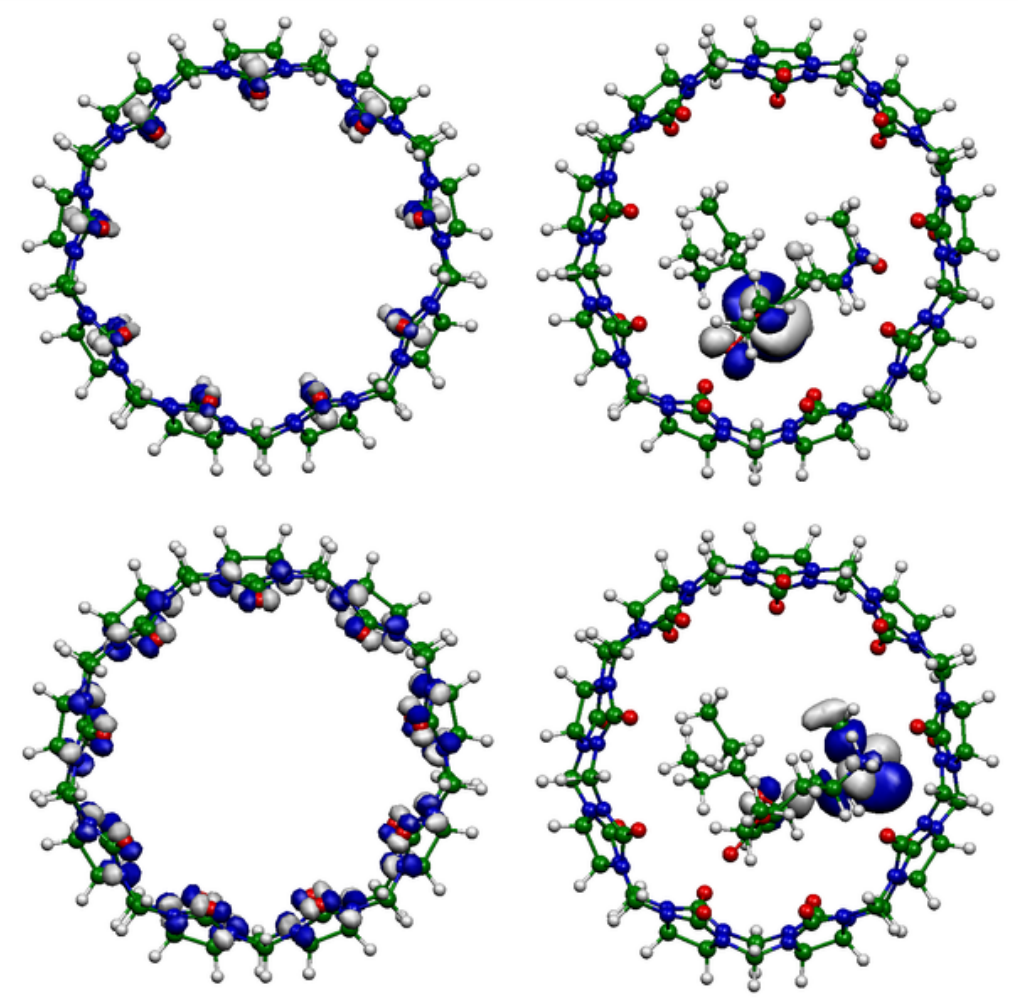

(e)

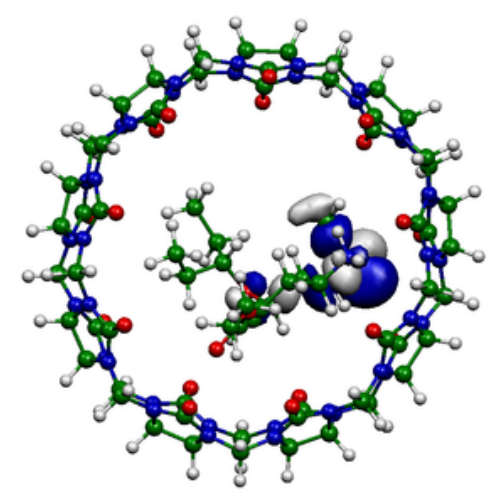

(f)

Figure 8

Plots of the LUMO (top) and the HOMO (bottom) orbitals of (a) CB[8], (b) CB[8]/OST-e, (c) CB[8]/OST-a, (d) CB[8]/OST-p, (e) CB[9], and (f) CB[9]/OST 


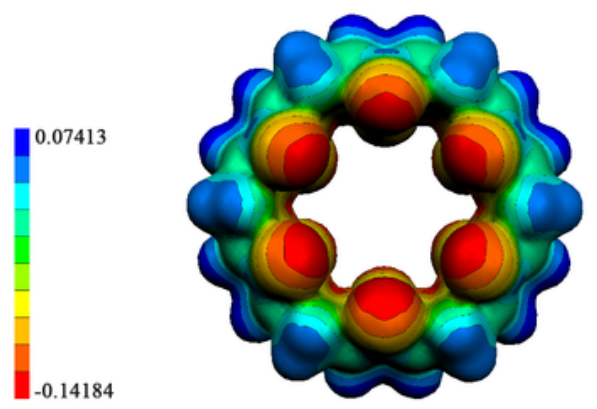

(a)
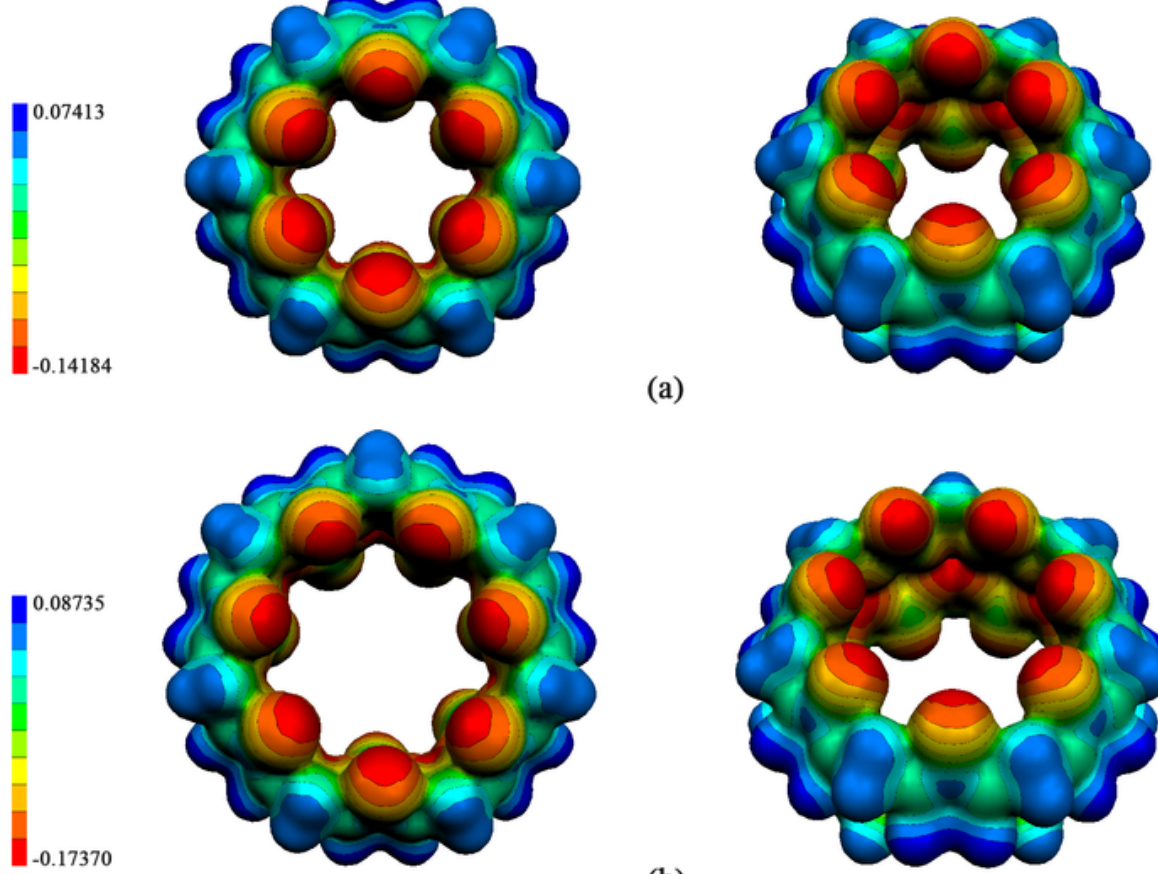

(b)
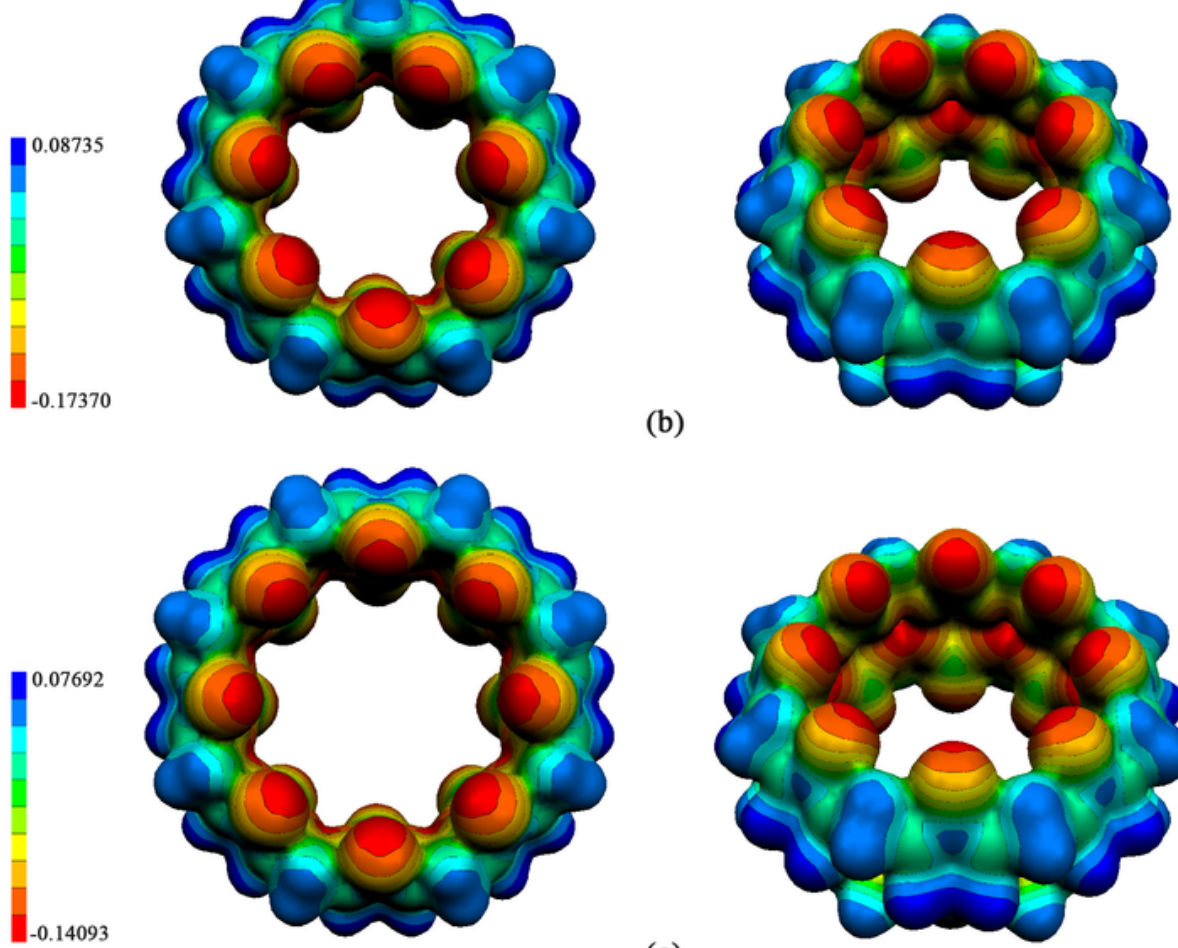

(c)
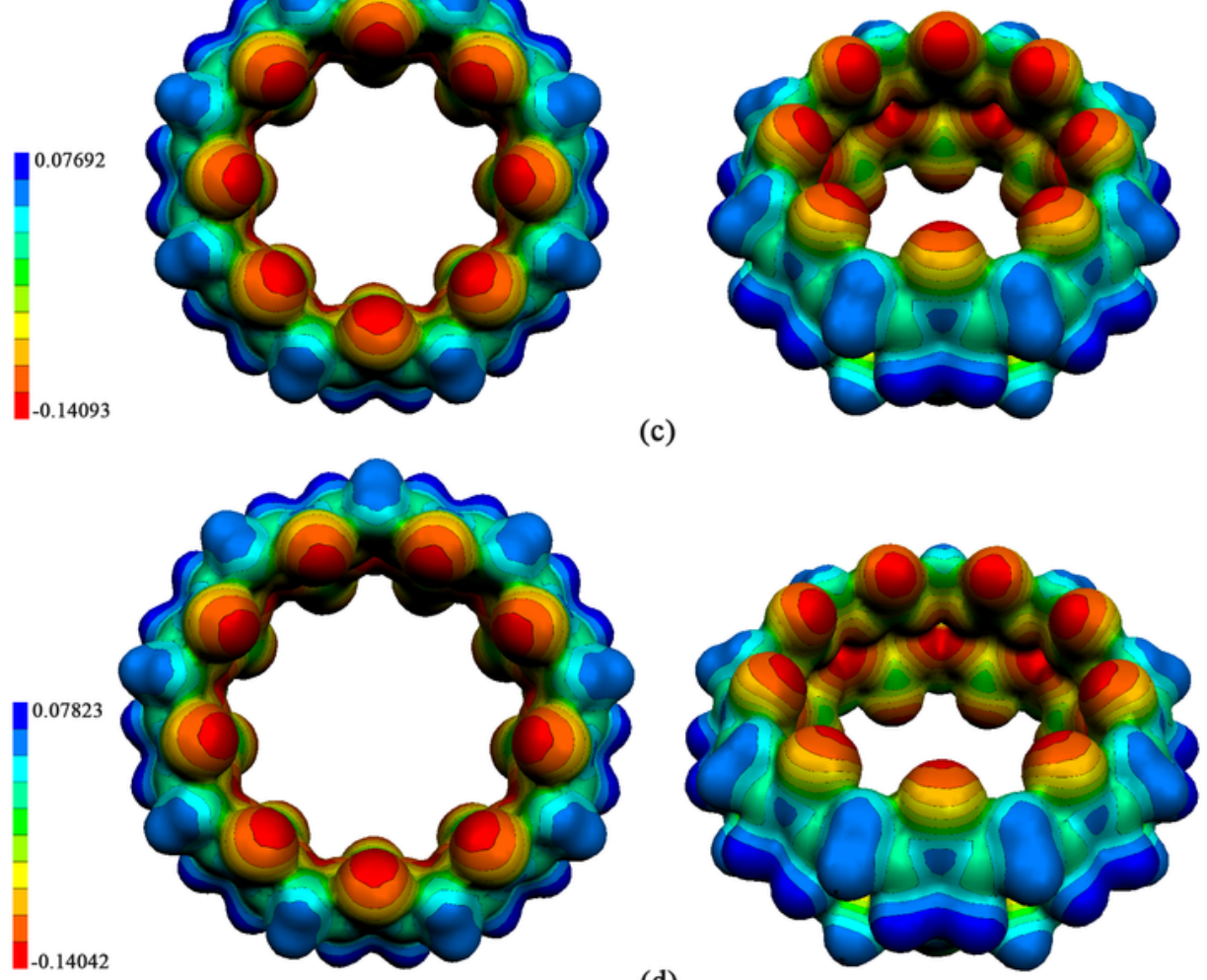

(d)

Figure 9

Computed molecular electrostatic potentials on the molecular surfaces of (a) CB[6], (b) CB[7], (c) CB[8], and (d) $\mathrm{CB}[9]$. Blue regions are more positive charges and red regions

are more negative charge 


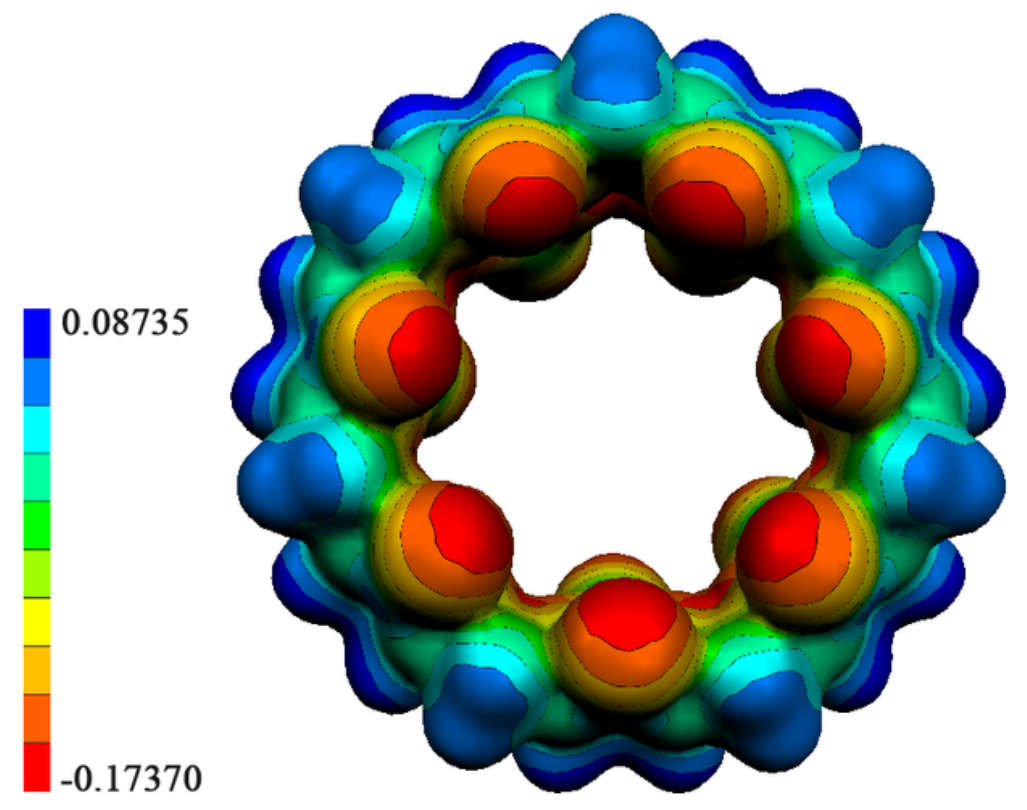

(a)
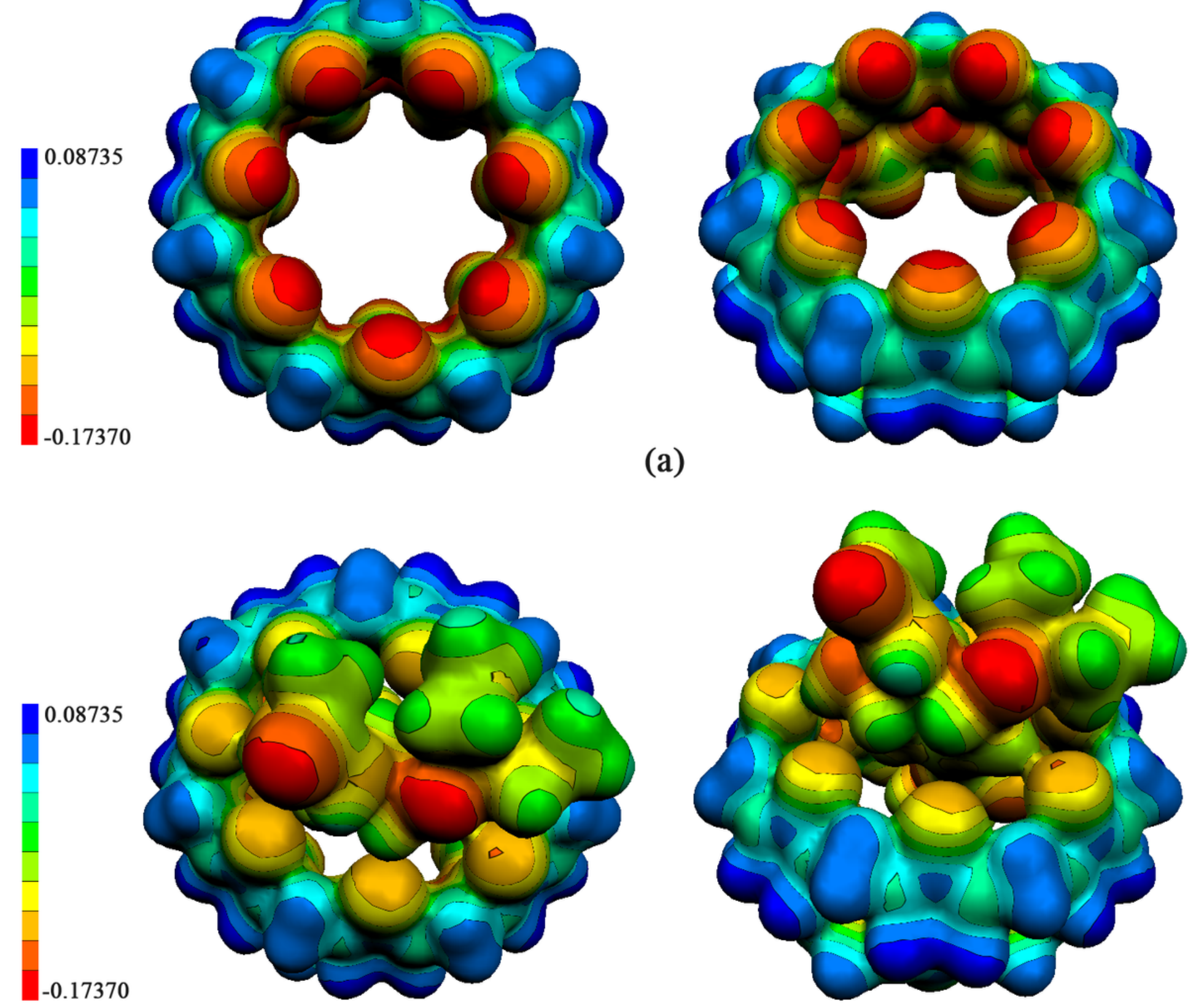

(b)

Figure 10

Computed molecular electrostatic potentials on the molecular surfaces of (a) CB[7], and (b) CB[7]/OST-e. Blue regions are more positive charges and red regions are more negative charge

\section{Supplementary Files}

This is a list of supplementary files associated with this preprint. Click to download. 
- Graphicabstract.doc

Page 23/23 